\title{
Stress and deformation of offshore piles under structural and wave loading
}

\author{
J. A. Eicher, H. Guan, and D. S. Jeng \\ School of Engineering, Griffith University, Gold Coast Campus, PMB 50 Gold \\ Coast Mail Centre, Qld. 9726, Australia
}

\begin{abstract}
Various offshore structures, especially large structures such as Tension Leg Platforms (TLP), are usually supported by concrete piles as the foundation elements. The stress distribution within such a large structure is a dominant factor in the design procedure of an offshore pile. To provide a more accurate and effective design for offshore foundation systems under axial and lateral wave loads, a finite element model is employed herein to determine the stresses and displacements in a concrete pile under similar loading conditions. A parametric study is also performed to examine the effects of the stress distribution due to the changing loading conditions.
\end{abstract}

Keywords: Offshore foundations, concrete pile, finite element analysis, wavestructure interaction.

\section{Introduction}

Concrete piles have been commonly used as foundation elements to support offshore structures such as bridges, oil-rigs, and floating airports. The use of offshore structures is still a new technique and there is still much research to be carried out in this field. The loading of an offshore structure consists of two components: vertical structural loads and lateral wave loads. The combinations of these two loading components have a significant impact on how the pile reacts and the way the stresses are distributed throughout the pile.

Wave forces on the offshore structures are the major contribution to the total forces experienced by such structures, particularly in rough weather. The calculation of the wave loads on vertical cylinders is always of major concern to ocean engineers, especially recently when such studies are motivated by the need to build solid offshore structures in connection with oil and natural gas productions. The effects of various wave patterns on offshore piles have been investigated by numerous researchers in the past (Au and Brebbia, 1983; Chakarabarti and Tam,

\# The corresponding author, Tel \& Fax: +61(7) 55528683 Email: d.jeng@mailbox.gu.edu.au 
1975; Raman et al., 1977; Zhu, 1993; Zhu and Moule, 1994). In addition, structural engineers have also carried out research on offshore piles, considering pile capacity (Tang, 1989) and the effects of the structural loads on offshore piles. However, little study has been found in the literature on the effects of the combined wave and structural loads on concrete piles.

The aim of this study is to investigate the effects of the combined loads on an offshore concrete pile and the effects of varying the loading parameters. The stress distributions within the offshore concrete pile will be estimated. The change in the stress distribution and displacement due to varying parameters to increase the pile strength will also be studied.

\section{Structural and Wave Loading}

\subsection{Vertical structural load}

The structural load is a vertical pressure load and is determined by using structural/water pressure ratios. The structural loads applied to the pile range from a ratio of zero, i.e. without structural load, to 10 times the static water pressure. Figure 1 shows all the loads acting together on the pile.

\subsection{Static water pressure}

The pressure that normal hydrostatic water exerts on a vertical surface can be found easily, varying only with the depth of the water. The pressure can be calculated as follows (Sorensen, 1997):

$$
p_{s}=-\gamma_{w} Z
$$

where $p_{s}$ is the static water pressure.

\subsection{Dynamic wave pressure}

Water depth and wave period are two essential wave parameters which must be considered in the design of any marine facilities. When the relative water depth (water depth/wave length, $d / L$ ) is greater than 0.5 , it is classified as deep water (Sorensen, 1997). In this paper, the three-dimensional short-crested waves are considered for the dynamic wave loading. Short-crested waves are created by winds blowing over the surface of the water and have a finite lateral extent. Zhu (1993) concluded that a short-crested wave exerts a smaller dynamic force than a plane wave with the same wave number in the same direction of propagation. However, as the wave number of short-crested waves perpendicular to the propagation of the plane waves increases, the total wave load increases. The first-order solution of the short-crested wave loading proposed by Zhu (1993) is used to calculate the wave 
load acting on the offshore concrete pile. The dynamic wave pressure at any point on the surface of the pile is given as (Zhu, 1993)

$$
p_{d}(a, \theta, z)=\frac{\gamma_{w} A}{2} \frac{\cosh k(z+d)}{\cosh k d} e^{-i \omega t} \sum_{m=0}^{\infty} \sum_{n=0}^{\infty} \varepsilon_{m} \varepsilon_{n} i^{m} Q_{m n}(a, \theta)
$$

where $p_{d}$ is the dynamic wave pressure acting on the pile, $a$ is the radius of the pile, $\theta$ is the angle around the circumference of the pile where the wave load is being calculated, and $z$ is the vertical depth from the surface of the water to the point where the wave load is being calculated.

In (2), $\gamma_{w}$ is the unit weight of water, $A$ is the amplitude of the waves being considered, $k$ ( $2 \pi / L, L$ is the wavelength) is the wave number, and $d$ is the total depth of the water. Figure 2 shows some of these variables. Also in (2), $i$ is equal to $\sqrt{-1}, \omega$ is the wave frequency, and $t$ is the second of the wave period that the wave load is being calculated.

In (2), parameters $\varepsilon_{m}, \varepsilon_{n}$ and $Q_{m n}(a, \theta)$ are defined as follows (Zhu, 1993)

$$
\begin{aligned}
& \varepsilon_{m}, \varepsilon_{n}= \begin{cases}1 & \text { when } m, n=0 \\
2 & \text { when } m, n \neq 0\end{cases} \\
& Q_{m n}(a, \theta)= {\left[J_{m}\left(k_{x} a\right) J_{2 n}\left(k_{y} a\right)-A_{m n} H_{m+2 n}(k a)\right] \cos (m+2 n) \theta } \\
&+\left[J_{m}\left(k_{x} a\right) J_{2 n}\left(k_{y} a\right)-B_{m n} H_{|m-2 n|}(k a)\right] \cos (m-2 n) \theta
\end{aligned}
$$

where

$$
\begin{aligned}
& A_{m n}=\frac{k_{x} J_{m}^{\prime}\left(k_{x} a\right) J_{2 n}\left(k_{y} a\right)+k_{y} J_{m}\left(k_{x} a\right) J_{2 n}^{\prime}\left(k_{y} a\right)}{k H^{\prime}{ }_{m+2 n}(k a)} \\
& B_{m n}=\frac{k_{x} J_{m}^{\prime}\left(k_{x} a\right) J_{2 n}\left(k_{y} a\right)+k_{y} J_{m}\left(k_{x} a\right) J_{2 n}^{\prime}\left(k_{y} a\right)}{k H^{\prime}{ }_{|m-2 n|}(k a)}
\end{aligned}
$$

in which $J($ ) represents the Bessel function of the first kind and $H($ ) represents the Hankel function. In (4), (5a), and (5b), the wave number in the $x$ - and $y$-directions, $k_{x}$ and $k_{y}$, can be expressed as

$$
k_{x}=k \cos \alpha \text { and } k_{y}=k \sin \alpha
$$

where $\alpha$ is the incident wave angle. 


\section{Numerical Analysis}

In this study, the finite element analysis package, STRAND7 (G+D Computing, 1999), is employed to calculate the deformation and stress within the concrete pile. The pile is modelled using 20-node brick elements except for the inner ring where 15-node wedge elements are used. A fixed support condition is provided at the points where the pile is embedded into the ocean bed. For the concrete pile, the Young's modulus is $28,600 \mathrm{MPa}$ and the Poisson's ratio is 0.2 .

\subsection{Convergence of model}

Before conducting a parametric study, a convergence test is performed under the structural load and the static water pressure to determine the most appropriate mesh. Based on the results from the convergence test, the wave pressure is then calculated and applied to the pile and the analyses are performed to find the resulting stress distributions as well as the resulting displacements.

Two series of convergence tests are performed. The first convergence test is to refine the mesh vertically above and below the surface water level. The second convergence test is to refine the mesh on the cross-section of the pile. In total, fifteen different models are used for the tests, including three variations of the mesh in the vertical direction on the surface water level (Models X, Y, and Z), and for each of these three models, five variations of mesh on the cross-section $(4,6,8,10$, and 12 rings). The basic model used as the control pile is modelled having a $1 \mathrm{~m}$ radius and a $20 \mathrm{~m}$ height. The water depth for the control model is $10 \mathrm{~m}$. The details of the different mesh schemes are shown in Fig. 3. It should be noted that due to the nature of a 20-node brick, the side nodes of each brick element form an intermediate row or ring of nodes.

The typical results of the convergence tests are presented in Figure 4. Figure 4(a) shows the von Mises stress at point A (refer to Figure 5(b)) versus the number of rings for Models $\mathrm{X}, \mathrm{Y}$, and $\mathrm{Z}$. The figure clearly indicates that the solution converges when the 6-ring model is adopted, with the change in slope between the 8, 10, and 12 ring models being very small. Figure 4(b) shows the vertical displacement at point A versus Models X, Y, and $\mathrm{Z}$ for all number of ring models. It is evident that the convergence is achieved when Model $\mathrm{Y}$ is used.

Based on the convergence study, Model $\mathrm{Y}$ with six rings is selected to simulate the control pile. This mesh has 1320 bricks and 5505 nodes. The numerical analysis is then carried out to include the static water pressure, the dynamic wave loads, as well as the varying structural loads.

\subsection{Effects of combined loading conditions}

After applying the loading conditions to the final model that is selected, the three-dimensional finite element analyses are performed. The results of these 
analyses show a significant difference in the stress distribution due to the different combination of the loads. Figure 5(a) shows the stress distribution of the centre surface of the pile due to the structural load of 10 times the static water pressure. Under such loading conditions, the stress distribution is found to be symmetrical about the vertical central axis of the pile. The stress distribution due to the same structural load together with the dynamic wave loads, which is at $t=2$ seconds of a 10-second wave period (see Figure 5(b)), illustrates how the stress concentrations change around the base of the pile. It should be noted that the location of the highest stress concentration varies over the period of a wave.

\subsection{Parametric study of wave loads}

One of the major concerns of this study is to examine the effects of a changing loading condition on the offshore pile. A study is done to determine the effects of varying parameters of the dynamic wave loading. The three parameters that are used to complete this study are the wave period $(T)$, the wave height $(H)$, and the incident wave angle $(\alpha)$. Three control values are used to ensure an accurate comparison of the varying parameters, i.e., $T=10$ seconds, $H=1 \mathrm{~m}$ and $\alpha=15^{\circ}$.

\subsubsection{Effects of wave periods}

The wave period is increased from 7.5 seconds to 10, 12.5 and 15 seconds. Figure 6(a) reflects the change in total displacement at Point A for each different wave period as the time and wave period ratio $(t / T)$ increases. Note that the total displacement is a resultant of the displacements in the $x-, y$-, and $z$ - directions. As seen in the figure, the total displacement peaks twice throughout the wave period, once at about $1 / 4$ of the wave period and again at about $3 / 4$ of the wave period. The displacement remains approximately the same at the start, middle, and the end of the wave period; however, as the period increases from 7.5 seconds to 10 seconds, the peak displacement at the $1 / 4$ period and at the $3 / 4$ period points decreases by about $14 \%$. Again, as the wave period increases from 10 seconds to 12.5 seconds, the peak displacement decreases by an additional 9\%. As the wave period increases from 12.5 seconds to 15 seconds, the peak displacement deceases again by an additional 3\%. This totals about 26\% decrease in total displacement as the wave period increases from 7.5 second to 15 seconds.

Figure 6(b) illustrates the changes in stress throughout the period of a wave at Point $\mathrm{A}$ as the wave period increases. As seen, the stress at this point remains approximately the same as the wave period increases, with the two peak stresses being at about $1 / 3$ and $2 / 3$ the wave period. A non-dimensional expression is used to represent the change in stress, by dividing the resulting stress by $\gamma_{w} H / 2$ cosh $k d$, where $H$ is the wave height.

The variation of displacement and stress against $z / h$ are presented in Figures 7(a) and 7(b) respectively, where $h$ is the height of the pile. The resultant displacements and stresses are predicted over the height of the pile at $2 \mathrm{~m}$ intervals, beginning $2 \mathrm{~m}$ 
above the base of the pile. The $x$ - and $y$-coordinates are kept the same at each point when the $z$-coordinate increases. Referring to Figure 1 for a definition of the global axes system. The results shown in Figure 7(a) confirm the plot shown in Figure 6(a) in which the displacement at $t=0$ second is the same for each increasing time period over the entire length of the pile. The displacement increases linearly at a slope of $0.022 \mathrm{~mm}$.

Similarly, Figure 7(b) also corresponds to Figure 6(b) in that the stress is approximately the same over the height of the pile at $t=0$ second. The curvature in the line indicates that the stress increases up to the surface water level, where the stress levels off and remains constant until just before reaching the top of the pile. There is a significant increase in stress in the very top $1 \mathrm{~m}$ of the pile where the structural load is applied.

\subsubsection{Effects of wave heights}

The wave height is increased from a $1 \mathrm{~m}$ height, the control value, to a $5 \mathrm{~m}$ height. Figure 8(a) demonstrates the change in total displacement at Point A over the period of a wave. Opposite to the effects of increasing wave period, the total displacement increases as the wave height increases. The total displacement peaks twice during the wave period, once at $1 / 5$ the period and again at $4 / 5$ the period. At a $2 \mathrm{~m}$ wave height, the peak displacement is about $60 \%$ greater than that obtained at the control height. Increasing the height again, at $3 \mathrm{~m}$, the peak displacement is about $125 \%$ greater. At $4 \mathrm{~m}$ and $5 \mathrm{~m}$ wave heights, the increase in the peak total displacement is $190 \%$ and $260 \%$, respectively, greater than the control height of 1 $\mathrm{m}$.

Figure 8(b) illustrates the non-dimensional change in stress at Point $\mathrm{A}$ as the wave heights increase. The non-dimensional expression is obtained by dividing the resulting stress by $\gamma_{w} d / 2 \cosh k d$. Similar to the variation of the stress diagram due to the increasing wave periods, the two peak stresses are at approximately $1 / 3$ the wave period and 2/3 the wave period. The stresses at the beginning, middle, and the end of the period actually decrease as the wave height increases; however, the variation in stress increases with the height of the wave.

Figure 9 displays the results of the increasing wave heights over the height of the pile. In Figure 9(a), the total displacement increases linearly at a slope of $0.022 \mathrm{~mm}$. These results are again reflected by Figure 8(a) where at $t=0$ second the wave height does not affect the displacement at point A for varying wave periods.

The von Mises stress distribution in the piles due to the increasing wave height is shown in Figure 9(b). The stress in the top half of the pile remains constant as the wave height increases. However, at the surface water level, the stress begins to decrease as the wave height increases, but retaining a similar value for all wave heights at the base of the pile. These results also correspond to Figure 8(b) when 
$t=0$ second. At point A $(\mathrm{z} / \mathrm{h}=0.5)$, the stress decreases as the wave height increases from $1 \mathrm{~m}$ to $5 \mathrm{~m}$.

\subsubsection{Effects of incident wave angles}

The incident wave angle is increased from $0^{\circ}$ to $90^{\circ}$, at $15^{\circ}$ intervals. Figure 10(a) portrays the change in total displacement at Point A over the period of a wave. It is found that the total displacement decreases as the incident wave angle increases around the circumference of the pile. The total displacement peaks twice during the wave period, once at $1 / 5$ the period and again at $4 / 5$ the period. At a $90^{\circ}$ angle, the peak displacement is about $32 \%$ less than that at a $0^{\circ}$ incident wave angle. The decrease in displacement from $0^{\circ}$ to $15^{\circ}$, the control value, is less than $2 \%$. Increasing the angle to $30^{\circ}, 45^{\circ}, 60^{\circ}$, and $75^{\circ}$, the total displacements are about $7 \%$, $14 \%, 22 \%$, and $28 \%$ respectively, less than the deflection for a $0^{\circ}$ incident wave angle. By $90^{\circ}$, the variation in displacement over the wave period is very small, just over $1 \%$ difference. The maximum variation in displacement, for $0^{\circ}$, is about $32 \%$.

Using the same non-dimensional ratio employed for studying the variation of the wave heights, the change in stress at Point A over the period of a wave is illustrated in Figure 10(b). It can be seen that the change in stress is approximately the same for all incident wave angles. Again the peak stresses occur at 1/3 and 2/3 the wave period, having a maximum change in stress of less than $1 \%$.

The variation of displacement and stress against $z / h$ are presented in Figures 11(a) and 11(b) respectively, where $h$ is the height of the pile. The resulting displacement and stress is predicted at $2 \mathrm{~m}$ intervals over the height of the pile and at $t=2 \mathrm{~s}$ of the wave period. The results shown in Figures 10(a) and 11(a) also correspond when $z / h=0.5$ (point A), in that the displacement at $t=2 \mathrm{~s}$ (where $t / T=0.2$ ) decreases as the incident wave angle increases. The displacement increases linearly, but the slope decreases as the incident wave angle increases. The displacement for an incident wave angle of $0^{\circ}$ increases at a slope of approximately $0.036 \mathrm{~mm}$. The displacements for incident wave angles of $15^{\circ}, 30^{\circ}, 45^{\circ}, 60^{\circ}, 75^{\circ}$, and $90^{\circ}$ decrease at slopes of approximately $0.035 \mathrm{~mm}, 0.033 \mathrm{~mm}, 0.030 \mathrm{~mm}, 0.026 \mathrm{~mm}, 0.024 \mathrm{~mm}$, and $0.022 \mathrm{~mm}$ respectively.

Similarly, when $t=2$ seconds, Figure 10 (b) is reflected by Figure 11(b) in that the stress remains approximately the same at point $A$, which is at $z / h=0.5$. The curvature in the line indicates that the stress increases up to the surface water level, where the stress levels off and remains constant until just before reaching the top of the pile. Only below the water surface is there a variation in stress as the incident wave angle varies. As the incident wave angle increases, the von Mises stress increases, with the greatest increase in stress being at the base of the pile.

\subsection{Parametric study of pile strength}


Another main concern of this study is how the strength of the pile affects it's behaviour under combined structural and wave loading. To undertake this study, a 20-meter control pile was used, with first varying the strength of concrete, followed by adding steel reinforcement to the pile.

\subsubsection{Effects of concrete strength}

To compare the effects of increasing the concrete strength, four different values of the mean concrete strength, $f_{c m}$, are used: 25, 32, 40, and $50 \mathrm{MPa}$. Figure 12 illustrates the results of the stress and displacement of the pile over the wave period of $10 \mathrm{~s}$. These results are shown at point A located on the surface of the pile (refer to Figure 5(b)). In Figure 12(a), it is seen that the displacement decreases at decreasing intervals as the concrete strength increases. At $t=2 \mathrm{~s}$ (where $t / T=0.2$ ) the displacement decreases by approximately $0.020 \mathrm{~mm}, 0.015 \mathrm{~mm}$, and $0.015 \mathrm{~mm}$ respectively as the concrete strength increases. The decreases in displacement are constant throughout the entire wave period.

A similar curve is shown for the von Mises stress as observed for the previous tests on varying wave loads. Again, the same non-dimensional ratio is used to represent the change in stress over the wave period. Even though the displacement decreases as the concrete strength increases, the stress in the pile is not affected by this change. The stress remains constant, with the peak stresses being at $1 / 3$ and 2/3 the wave period.

The variation of displacement and stress against $z / h$ are presented in Figures 13(a) and 13(b) respectively, where $h$ is the height of the pile. The resulting total displacement and von Mises stress is predicted over the height of the pile, at 2-meter intervals. These results are shown at $t=0 \mathrm{~s}$ of the wave period. It is seen in Figure 13(a) that the displacement increases linearly with a decreasing slope as the concrete strength increases. The slope of displacement over the pile height for a concrete strength of $25 \mathrm{MPa}$ is approximately $0.025 \mathrm{~mm}$, decreasing to $0.022 \mathrm{~mm}, 0.020 \mathrm{~mm}$, and $0.018 \mathrm{~mm}$ respectively as the strength increases. The total displacement at the base of the pile remains basically unchanged for different concrete strengths, with the greatest variation of displacement being at the very top of the pile.

The variation in stress over the height of the pile, as shown in Figure 13(b), has a similar curve as obtained in the previous tests on varying wave loads. The stress increases from the base of the pile up to the water surface, levelling off and remaining constant to just before the top of the pile. Results also indicate that increasing the concrete strength has no effect on the stress distribution throughout the pile, as reflected in Figure 12(b) at point A.

\subsubsection{Effects of steel reinforcement}

The most common method to increase the strength of a concrete pile is to add steel reinforcement. The second test carried out to study the effects of increasing the pile strength is to add a steel reinforcement cage. Standard $36 \mathrm{~mm}$ diameter steel 
reinforcing bars are used with circular ties. Under the applied loads, the minimum amount of reinforcement is adequate. In the finite element model, the reinforcing bars are modelled as beams, with a geometry of that of a $36 \mathrm{~mm}$ diameter steel bar, a Young's modulus of $2 \times 10^{5} \mathrm{MPa}$, and a Poisson's ratio of 0.25 . In this example, two models are compared, the control model without steel reinforcement and the other model with reinforcement.

The first set of results shown in Figure 14 are taken at point A (refer to Figure 5(b)) over the period of the wave. As seen in Figure 14(a), there is a reduction in the total displacement after the reinforcement is added to the control model. The maximum decrease in displacement is about $0.017 \mathrm{~mm}$ at the peaks of the sinusoidal displacement curve.

Figure 14(b) displays the curves of the stress distribution over the wave period, also at point A. The non-dimensional unit of stress is used to display the results, showing a significant decrease in the stress after steel reinforcement is added to the control model. This decrease of approximately $6 \%$ in stress is uniform over the entire wave period.

The second set of results taken for the reinforcement test is to compare the stress and displacement over the height of the pile. These results are taken at $t=0 \mathrm{~s}$ of the wave period. In Figure 15(a), the total displacement again increases linearly over the height of the pile, with the displacement being almost identical at the base of the pile and the greatest variation in displacement being at the top of the pile. The slope of the displacement for the control model is approximately $0.022 \mathrm{~mm}$, which decreases to approximately $0.021 \mathrm{~mm}$ after the steel reinforcement is added.

The familiar stress curves are shown in Figure 15(b) to compare the variation in the von Mises stress distribution over the height of the pile. The stress increases from the base of the pile to the water surface, where it becomes constant until just before reaching the top of the pile. In the control model, the stress in the very top of the pile increases significantly, however, once the steel reinforcement is added, this dramatic increase in stress is eliminated. Also, towards the base of the pile, the variation in stress is different once the steel reinforcement is added to the pile. In the control model, the von Mises stress is at its minimum towards the base of the pile. Once the reinforcement is added, the stress actually increases again toward the base of the pile, with the minimum stress being at about $1 / 2$ the water depth.

\subsection{Effects of original model over the wave period}

To have a better understanding of the behaviour of the pile, a study is completed to see how the control model reacts to the control loading condition over the period of the wave. Again, the results are taken at ten different locations at 2 meter intervals over the height of the pile, beginning 2 meters from the base of the pile. These locations are on the surface of the pile with the same $x$ - and $y$-coordinates. 
Figure 16(a) shows the total displacement over the height of the pile for $t=0$ to $10 \mathrm{~s}$ of a 10-second wave period. At each of the ten locations on the pile, the displacement increases up to $t=2 \mathrm{~s}$ of the 10 -second wave period, then begins to fall back down. By $t=5 \mathrm{~s}$ of the period, the displacement is equal to that at $t=0 \mathrm{~s}$, then begins to increase again until $t=8 \mathrm{~s}$. The peak displacement at each location is at $t=8$ $\mathrm{s}$ after which the displacement again falls back down by $t=10 \mathrm{~s}$ which equals the displacement at time zero and the cycle begins again.

A similar results is seen in Figure 16(b) with the stress distribution. The stress above the surface water level remains constant throughout the wave period, but varies greatly towards the base of the pile. Similar to Figure 16(a), the von Mises stress begins the wave period at approximately $0.26 \mathrm{MPa}$, decreases down to 0.2 MPa by $t=2 \mathrm{~s}$ of the wave period when it begins to increase again. By $t=5 \mathrm{~s}$, the stress is equivalent to $t=0 \mathrm{~s}$, but then the stress begins to increase in the second half of the wave period. By $t=8 \mathrm{~s}$, the stress reaches a maximum of about $0.34 \mathrm{MPa}$ where it begins to decrease back down to the start by $t=10 \mathrm{~s}$, which is the beginning of a new cycle.

\section{Conclusion}

In this study, the deformation of and stresses in an offshore concrete pile under combined structural and wave loading is analysed by the finite element method. A control model is analysed using a specific set of control data, then compared to succeeding models as the pile and loading parameters are changed. The loading parameters used to complete this study are the wave period $(T)$, wave height $(H)$, incident wave angle $(\alpha)$. The pile strength parameters also used to complete the study are the mean concrete strength $\left(f_{c m}\right)$ and the amount of steel reinforcement. After compiling and analysing the results from each test, the following conclusions can be made:

(1) As the wave period increases the peak displacement of the pile significantly decreases so shorter wave periods have a more critical effect on the pile displacement.

(2) Increasing wave heights creates a dramatic increase on the peak displacement, while the minimum stresses actually decrease significantly.

(3) There is a dramatic decrease in the peak displacement as the incident wave angle increases away from the point of reference (point A used in this case refer to Figure 5(b)). In addition, the stress towards the base of the pile increases significantly as the incident wave angle increases, although it still remains less than the maximum stress at the top of the pile.

(4) Increasing the strength of concrete does significantly decrease the displacement over the entire wave period, but has no effect on the stress distribution within the pile.

(5) Adding steel reinforcement to the concrete pile does reduce the total displacement of the pile, but the greatest effect is a significant reduction in stress in the top half of the pile where the stress is greatest. 
A design procedure for a pile considering a short wave period should not be the same as a design procedure for a significantly longer wave period. Similarly, a pile subjected to wave heights of $1 \mathrm{~m}$ should not be designed according to the same procedure as location with wave heights of $5 \mathrm{~m}$. It is also shown in the results that to reduce the critical stress and to increase the pile strength, the addition of steel reinforcement is necessary. Using the results provided herein, more effective design codes can be formulated to take into account the behaviour of the pile to a specific loading conditions.

\section{References}

Au, M.C. and Brebbia, C.A. (1983). Diffraction of water waves for vertical cylinders using boundary elements. Applied Mathematical Modelling, 7, 106-114.

Chakarabarti, S.K. and Tam, A. (1975). Interaction of waves with large vertical cylinder. Journal of Ship Research, 19, 22-23.

G+D Computing (1999). Using Strand7: Introduction to the Strand7 finite element analysis system. Sydney, Australia.

Raman, H., Jothishankar, N. and Venkatanarasaiah, P. (1977). Non-linear wave interaction with vertical cylinder of large diameter. Journal of Ship Research, 21(1), 120-124.

Sorensen, R.M. (1997). Basic Coastal Engineering. New York: Chapman \& Hall.

Tang, W.H. (1989). Uncertainties in offshore axial pile capacity. Foundation Engineering: Current Principles and Practices. New York, pp. 833-847.

Zhu, S. (1993). Diffraction of short-crested waves around a circular cylinder. Ocean Engineering, 20(4), 389-407.

Zhu, S. and Moule, G. (1994). Numerical calculation of forces induced by shortcrested waves on a vertical cylinder of arbitrary cross-section. Ocean Engineering, 21(7), 645-662. 


\section{List of Figure Captions:}

Figure 1: Loading on the offshore pile.

Figure 2: Definition of variables in wave field.

Figure 3: Pile models used for convergence tests (a) control pile model and vertical mesh refinement at surface water level and (b) mesh refinement through crosssection.

Figure 4: Convergence of pile models (a) von Mises stress at point $A$ and (b) vertical displacement at point A.

Figure 5: Contour of stress distribution due to combined loading conditions (a) structural load and static water pressure and (b) structural load and static/dynamic wave pressure.

Figure 6: Responses at Point A with increasing wave period (T) (a) change in total displacement and (b) change in normalised von Mises stress.

Figure 7: Responses at $t=0 \mathrm{~s}$ with increasing wave period (T) (a) change in total displacement and (b) change in von Mises stress.

Figure 8: Responses at Point A with increasing wave height $(H)$ (a) change in total displacement and (b) change in normalised von Mises stress.

Figure 9: Responses at $t=0 \mathrm{~s}$ with increasing wave height $(H)(\mathrm{a})$ change in total displacement and (b) change in von Mises stress.

Figure 10: Responses at Point A with increasing incident wave angle ( $\alpha$ ) (a) change in total displacement and (b) change in normalised von Mises stress.

Figure 11: Responses at $t=0 \mathrm{~s}$ with increasing incident wave angle ( $\alpha$ ) (a) change in total displacement and (b) change in von Mises stress.

Figure 12: Responses at Point A with increasing mean concrete strength $\left(f_{c m}\right)(\mathrm{a})$ change in total displacement and (b) change in normalised von Mises stress.

Figure 13: Responses at $t=0 \mathrm{~s}$ with increasing mean concrete strength $\left(f_{\mathrm{cm}}\right)(\mathrm{a})$ change in total displacement and (b) change in von Mises stress.

Figure 14: Responses at Point A to compare piles with and without additional steel reinforcement (a) change in total displacement and (b) change in normalised von Mises stress. 
Figure 15: Responses at $t=0 \mathrm{~s}$ with the addition of steel reinforcement (a) change in total displacement and (b) change in von Mises stress.

Figure 16: Responses at different height locations over a 10-second wave period (a) change in total displacement and (b) change in von Mises stress. 

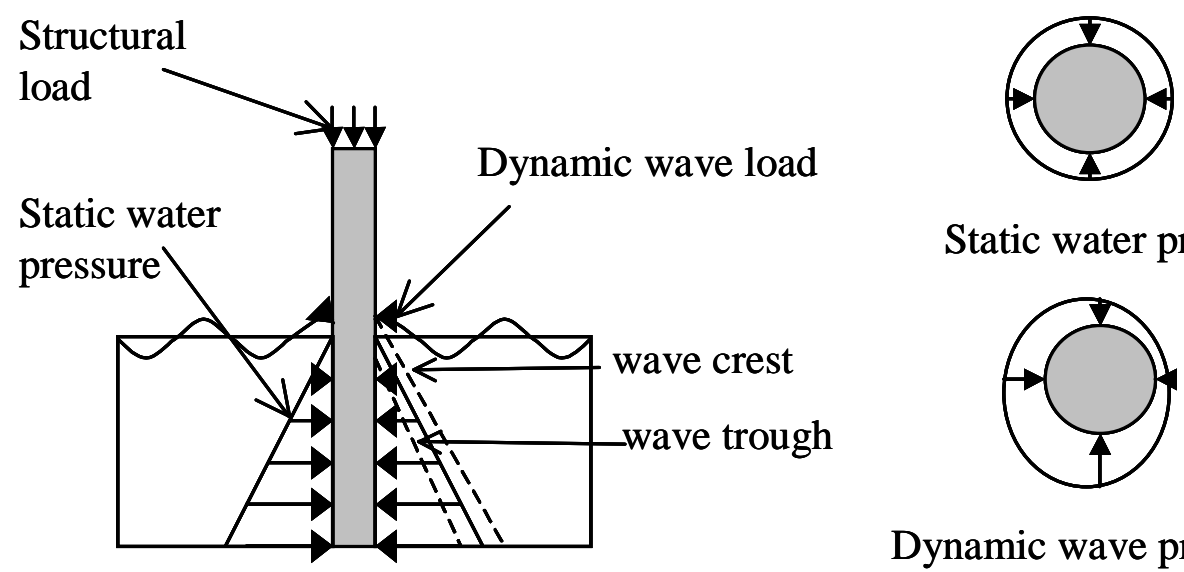

Static water pressure

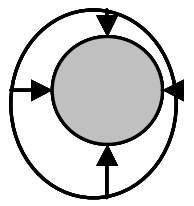

Dynamic wave pressure

Figure 1 


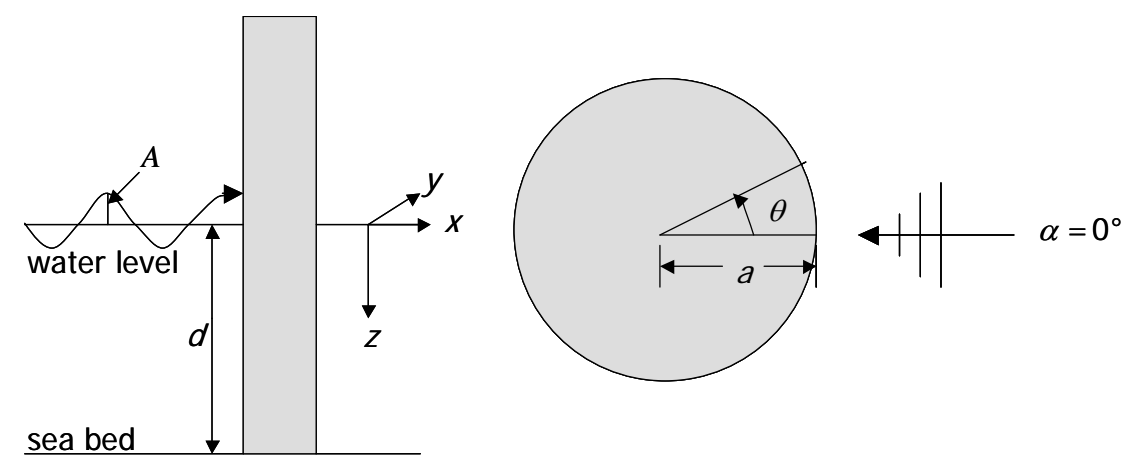

Figure 2 


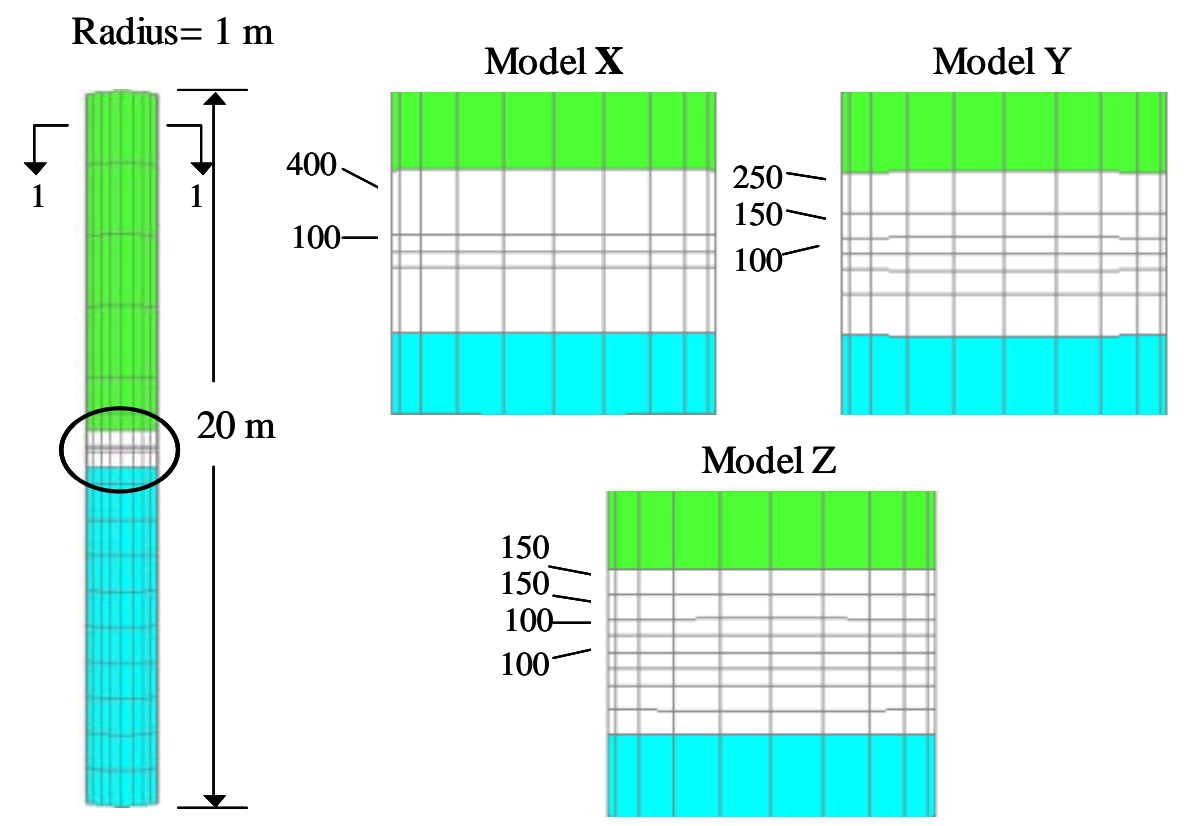

Figure 3(a) 


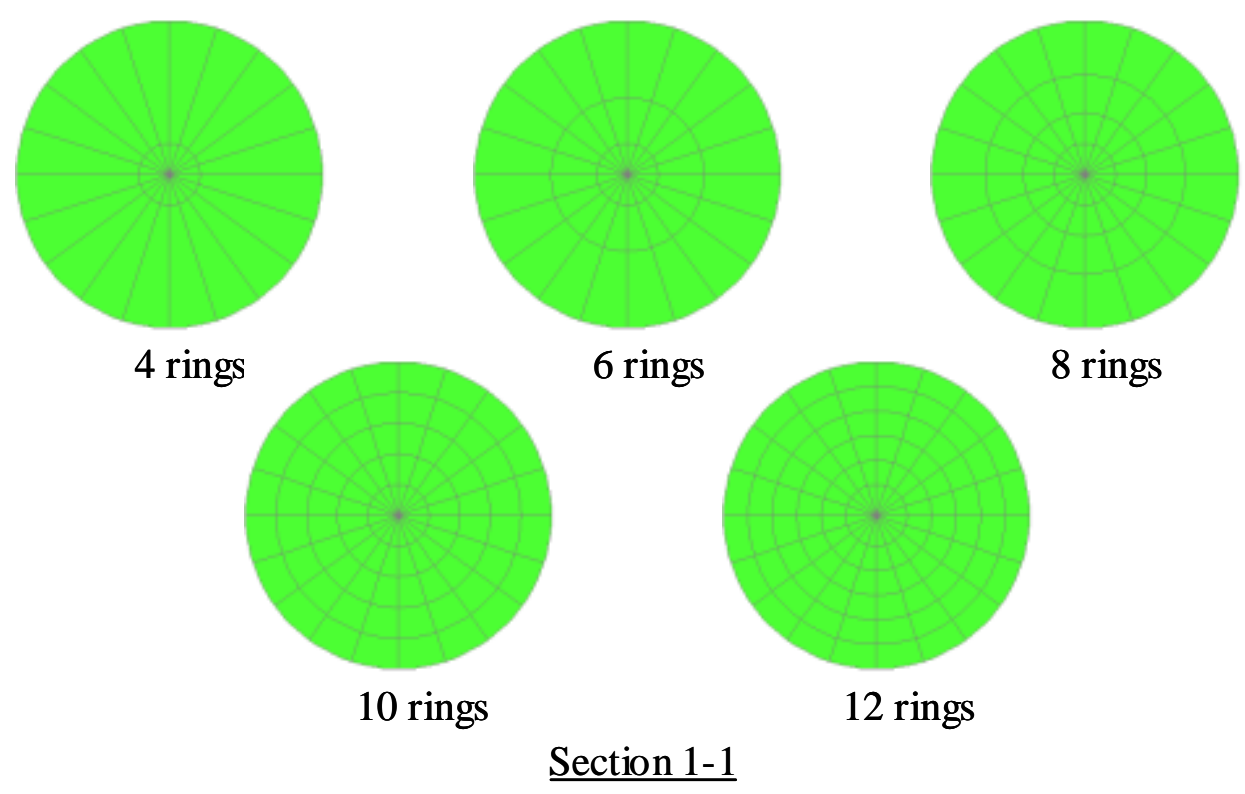

Figure 3(b) 


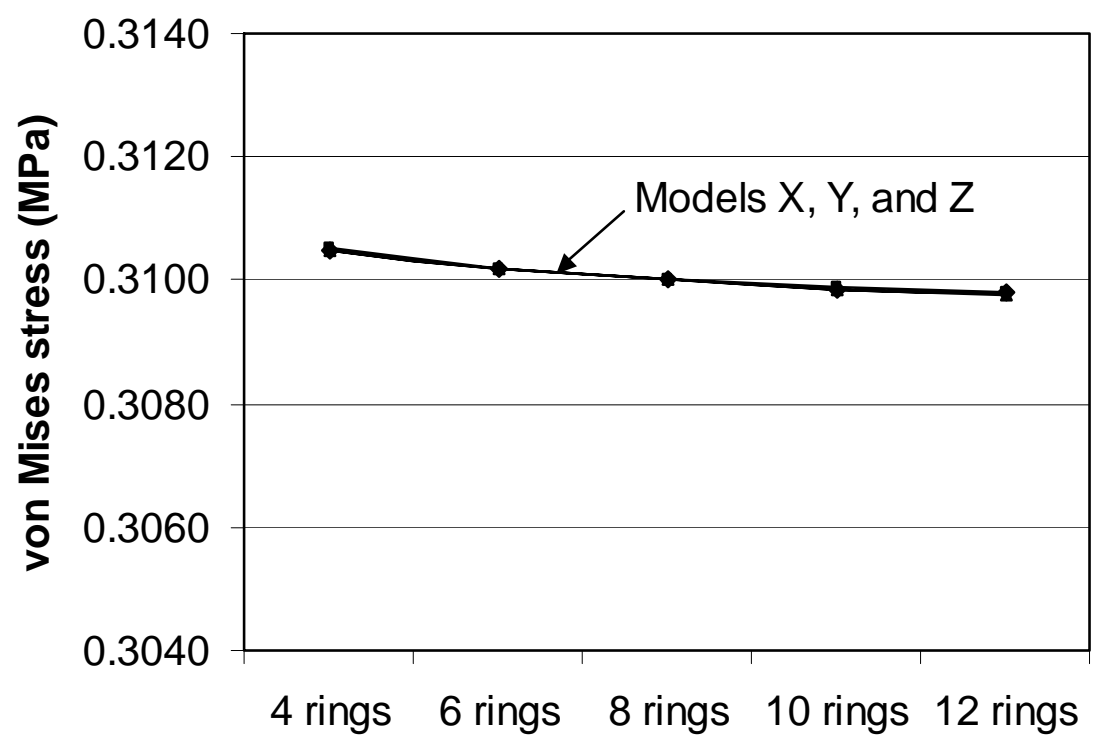

Figure 4(a) 


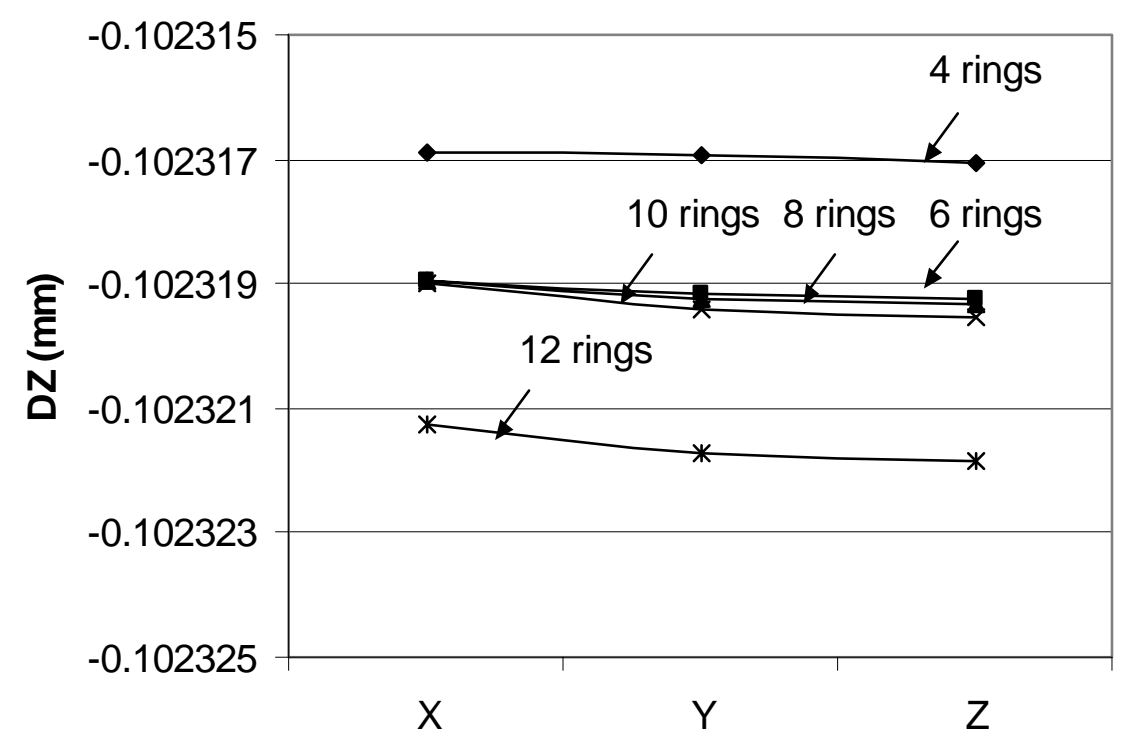

Figure 4(b) 
Brick Stress: von Mise (MPa)

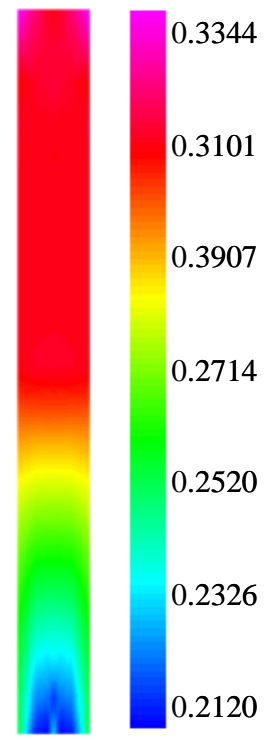

Brick Stress: von Mise (MPa)

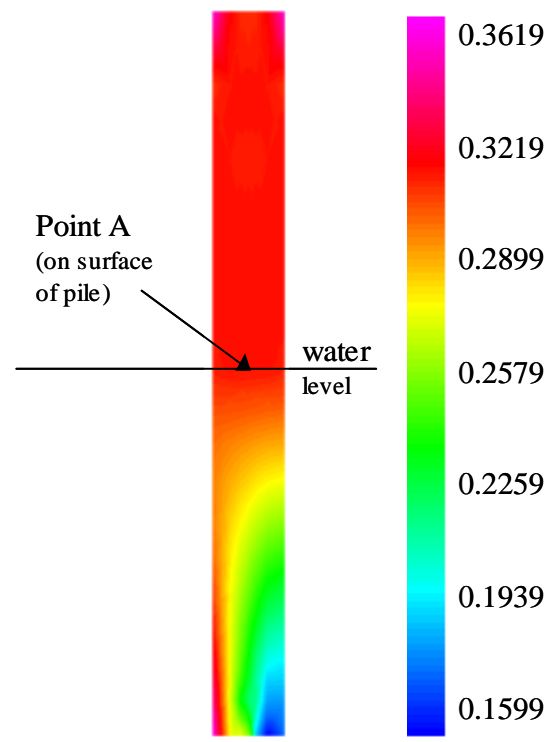

Figure 5 


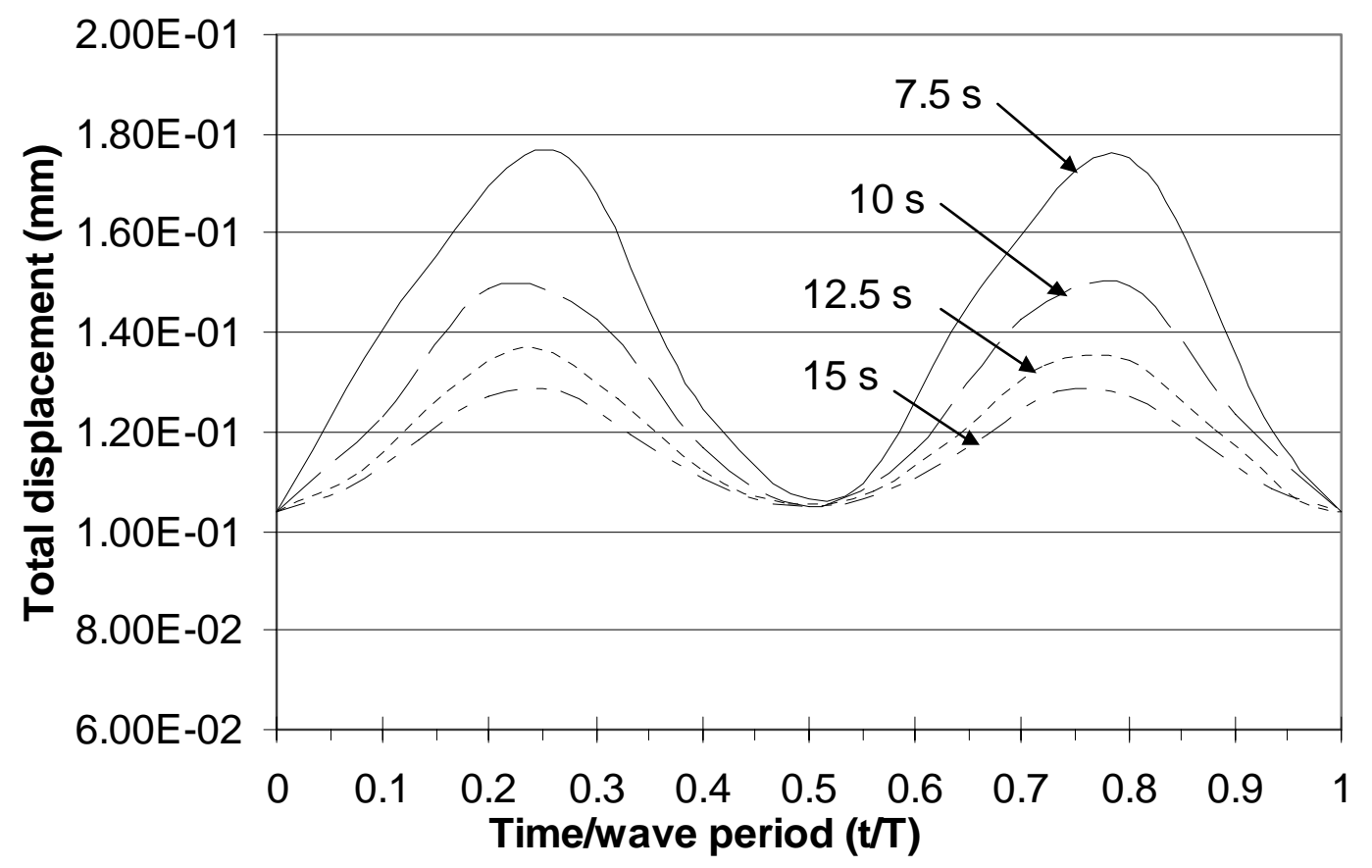

Figure 6(a) 


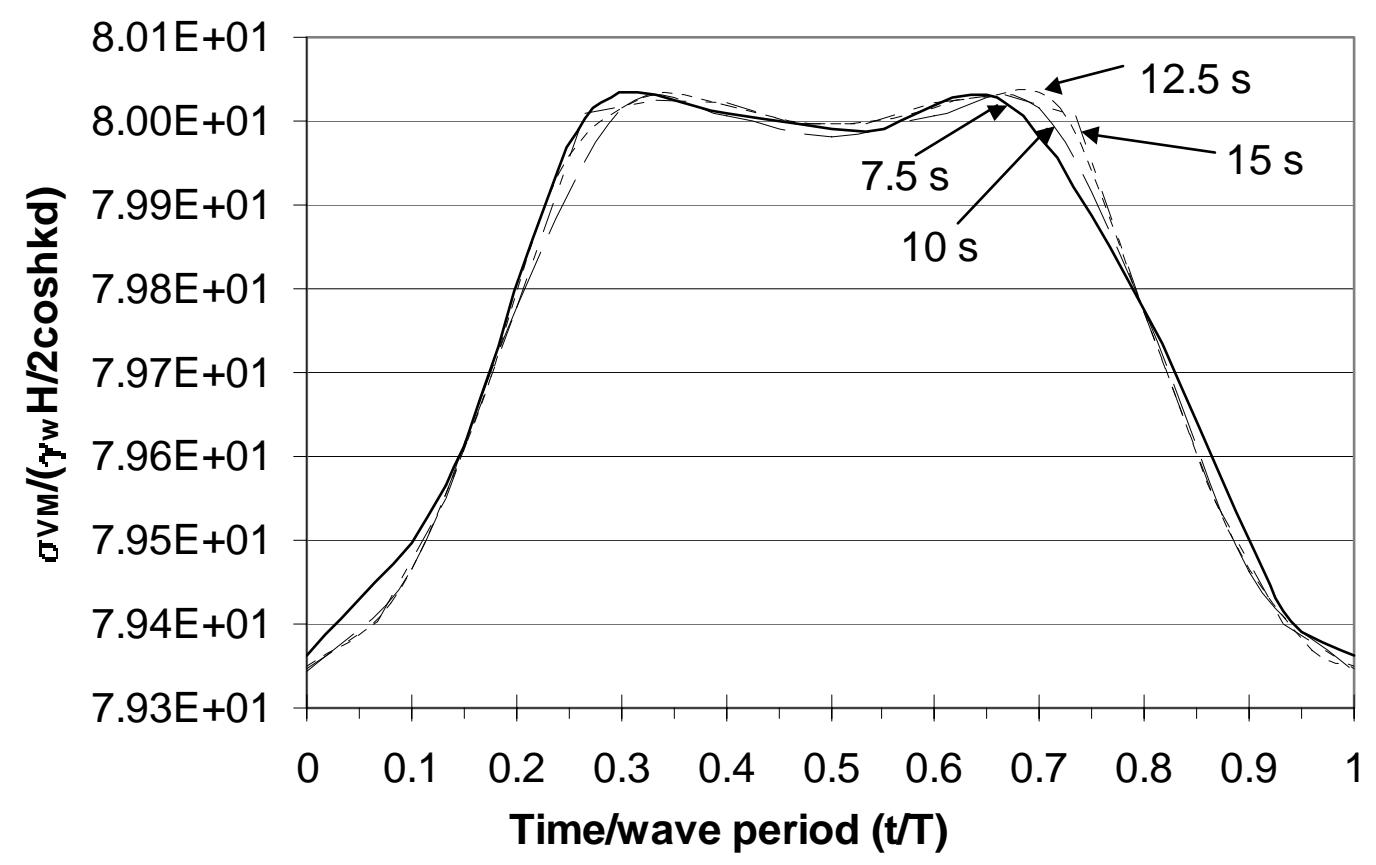

Figure 6(b) 


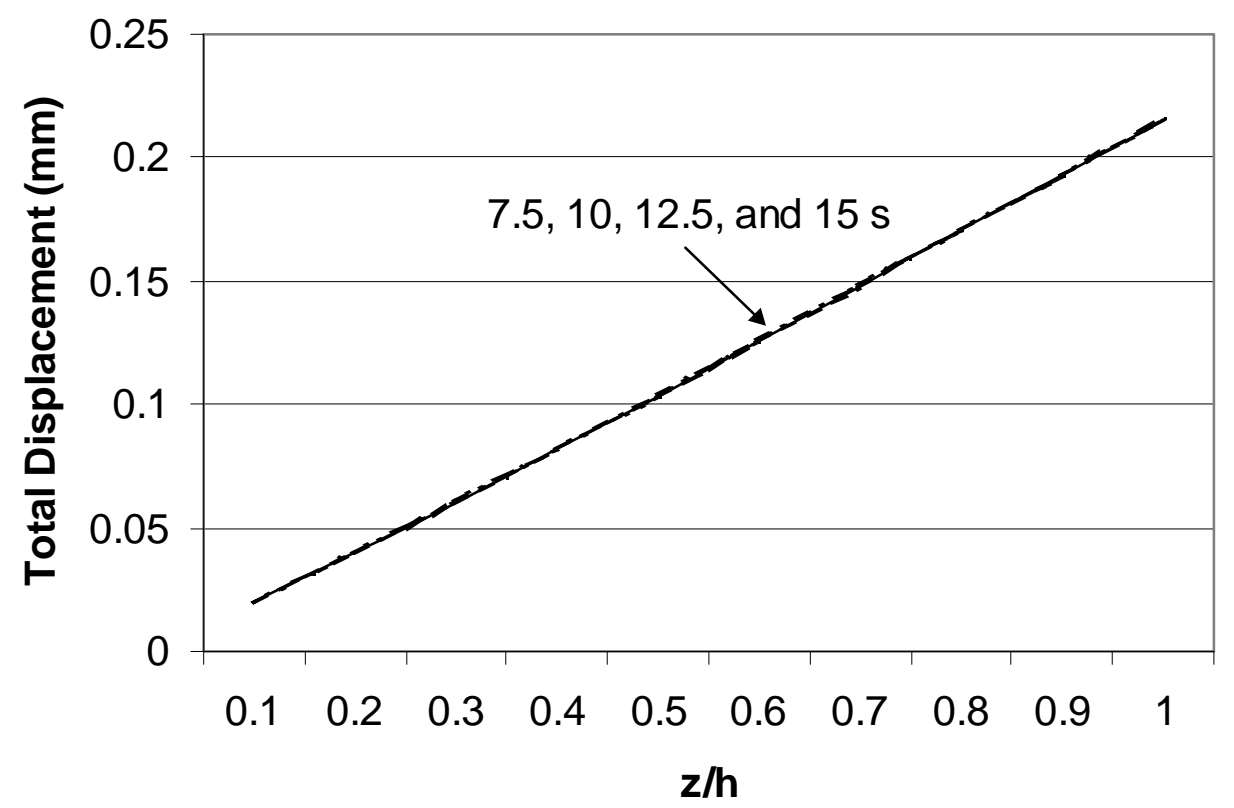

Figure 7(a) 


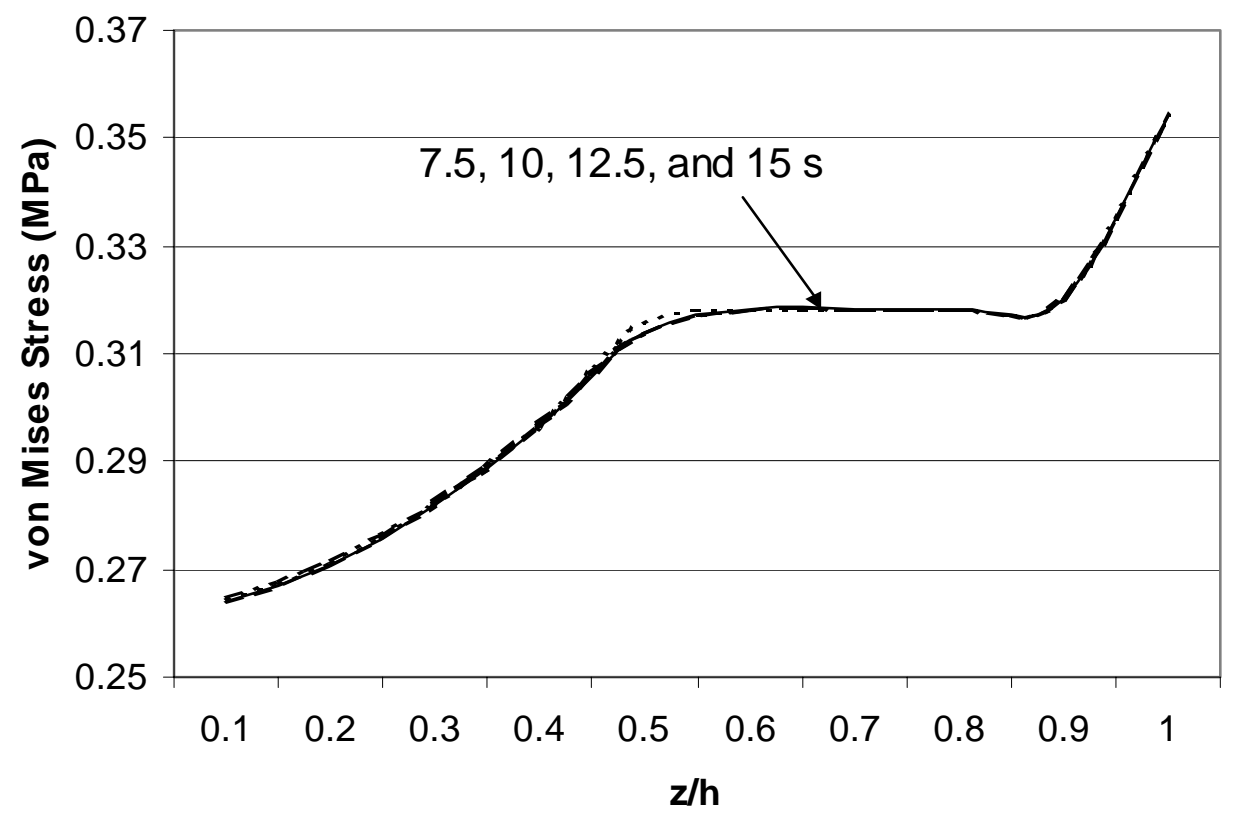

Figure 7(b) 


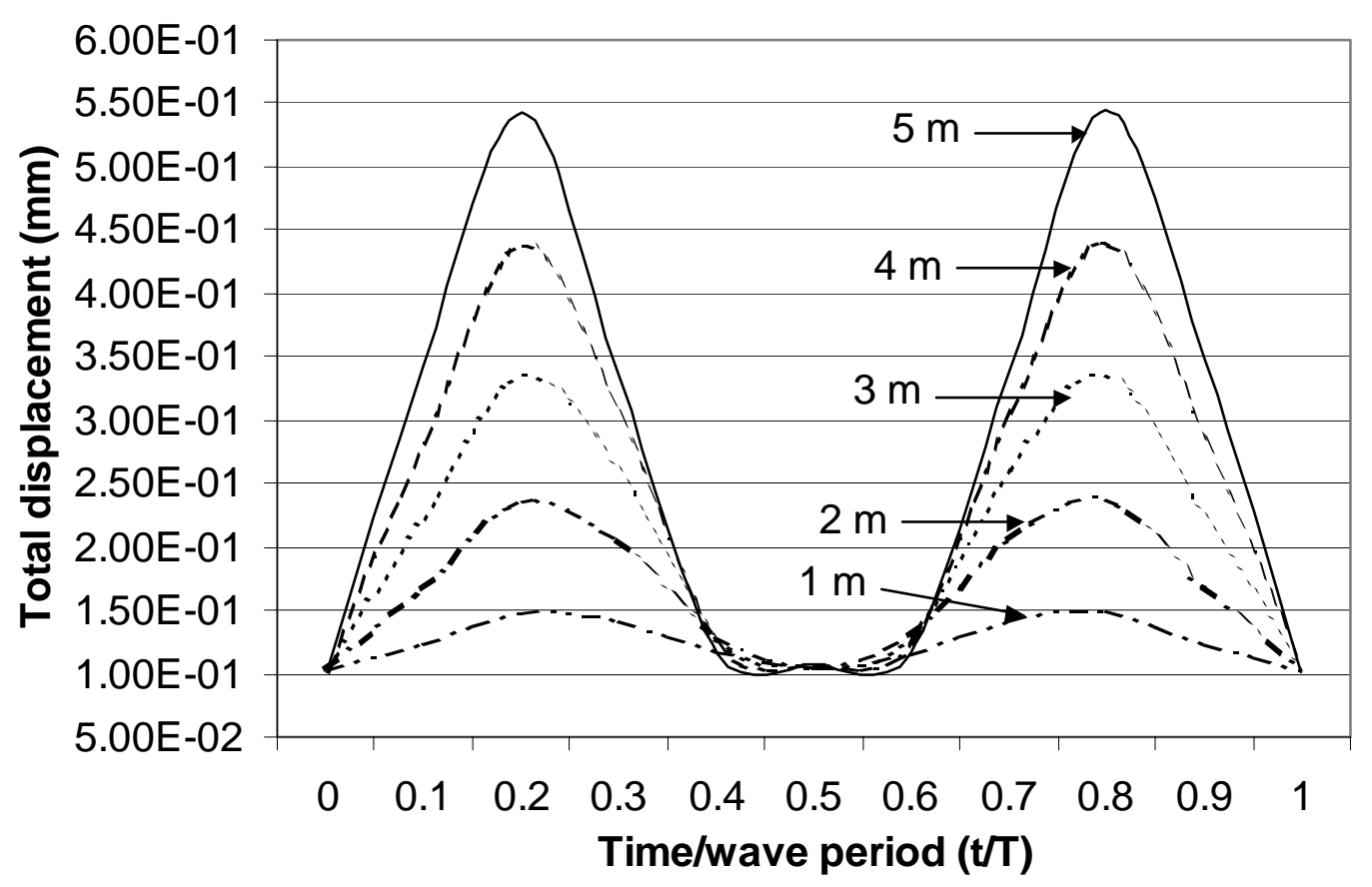

Figure 8(a) 


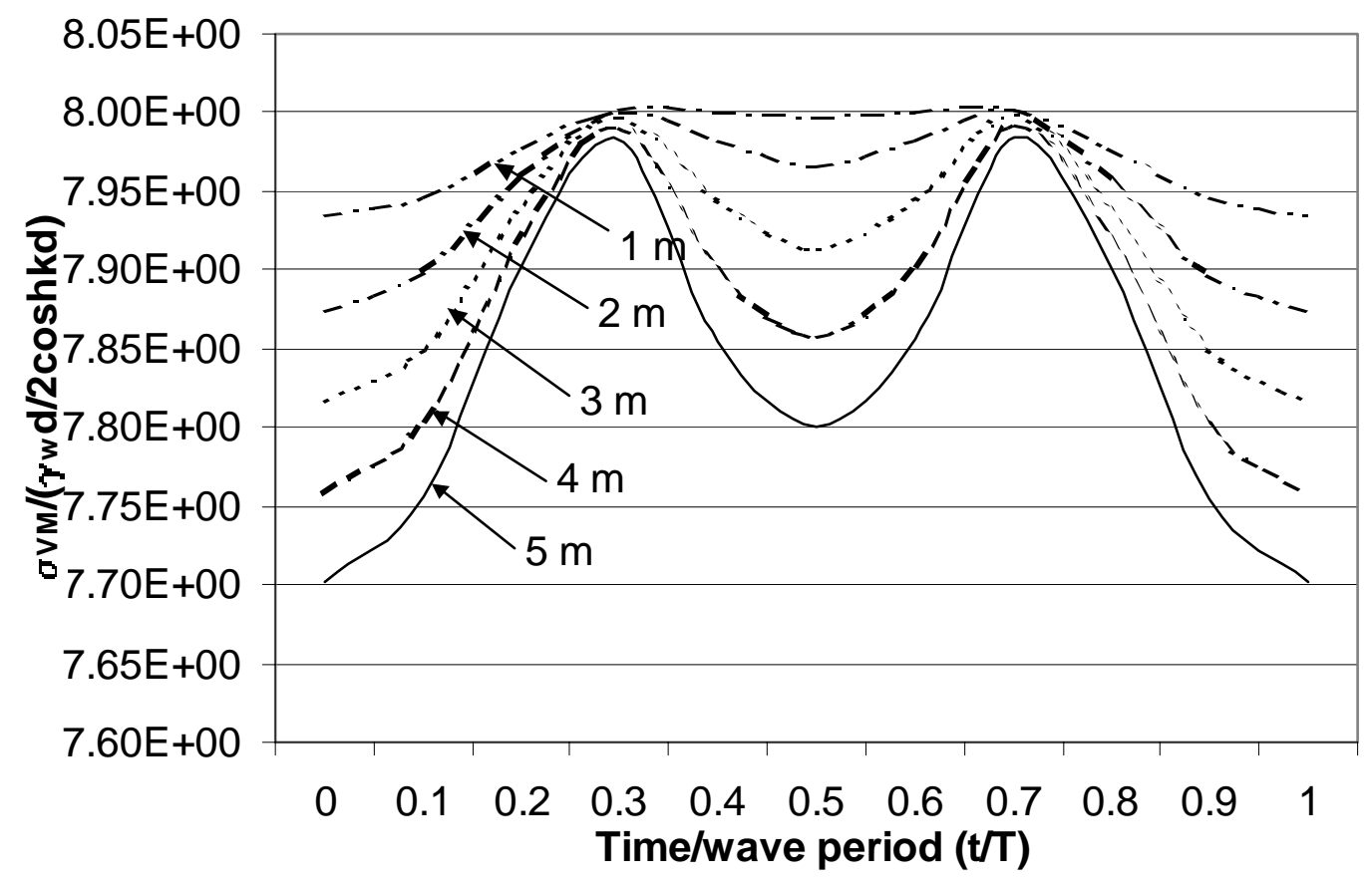

Figure 8(b) 


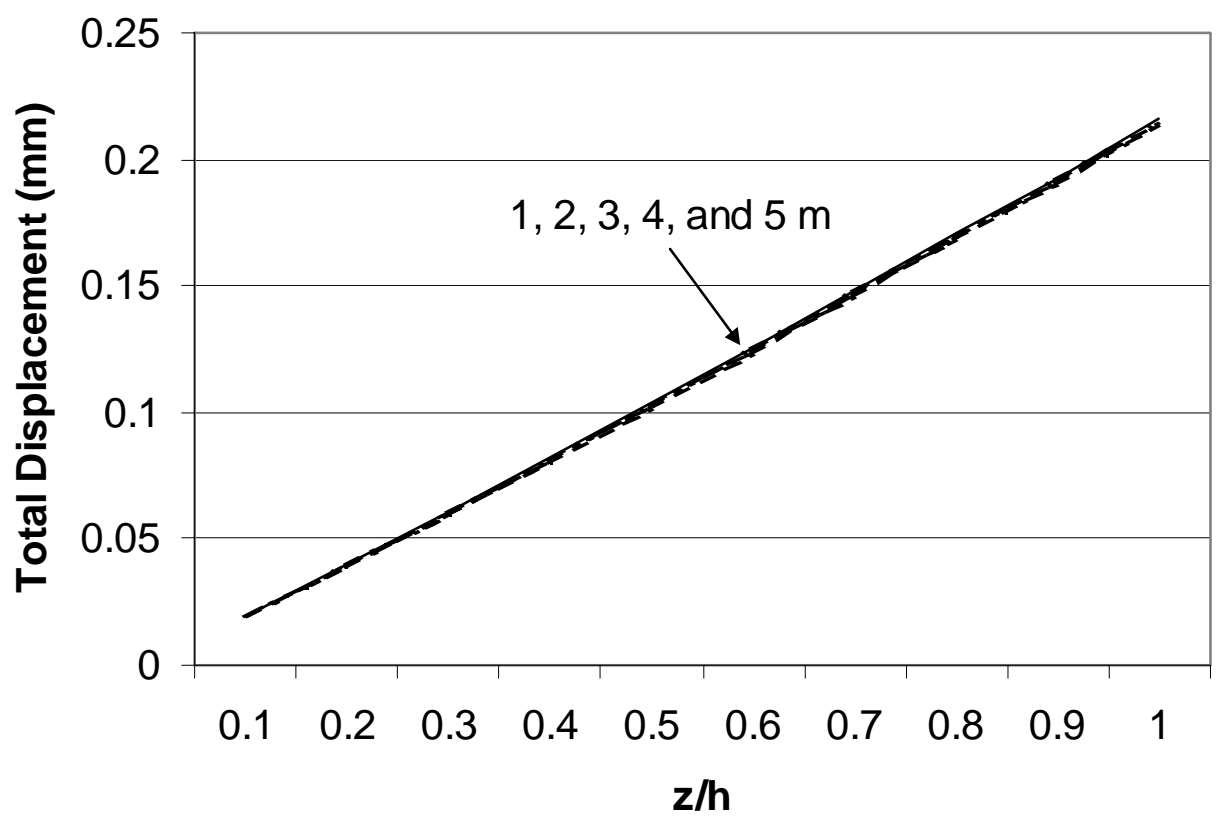

Figure 9(a) 


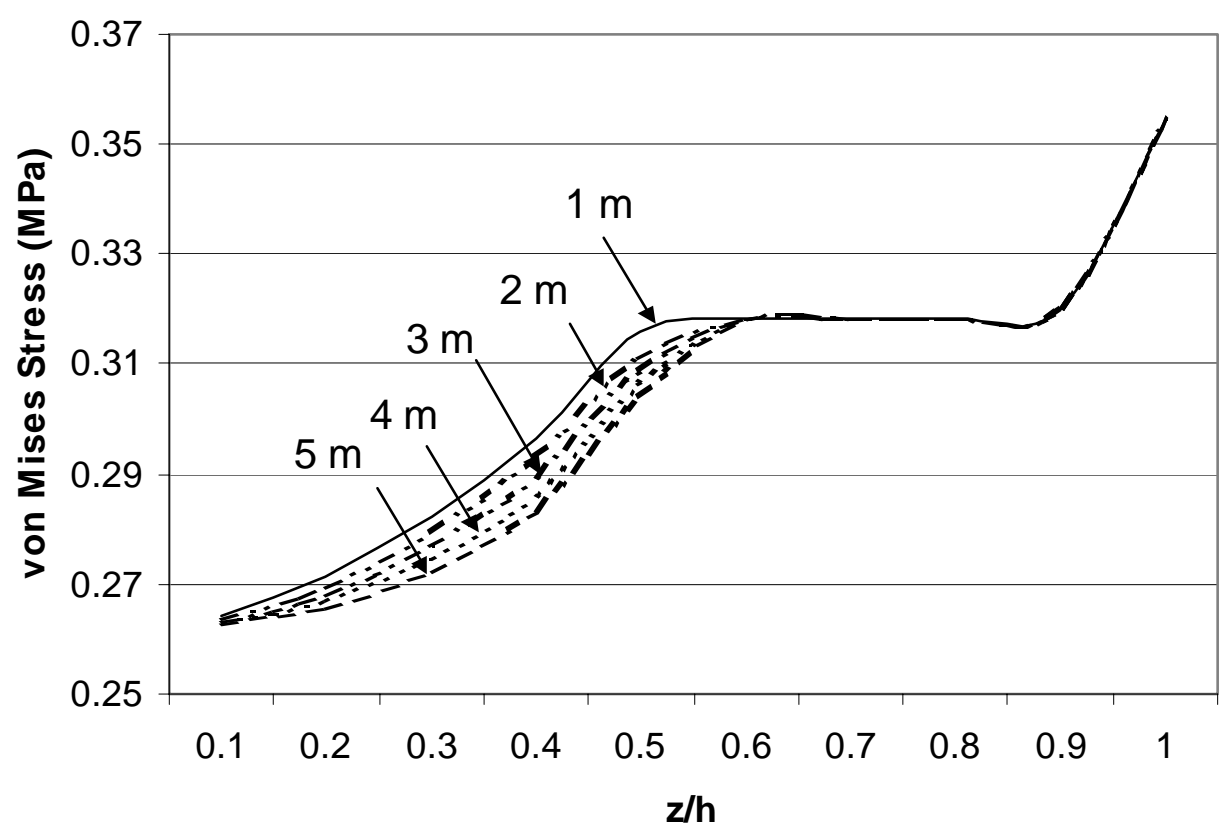

Figure 9(b) 


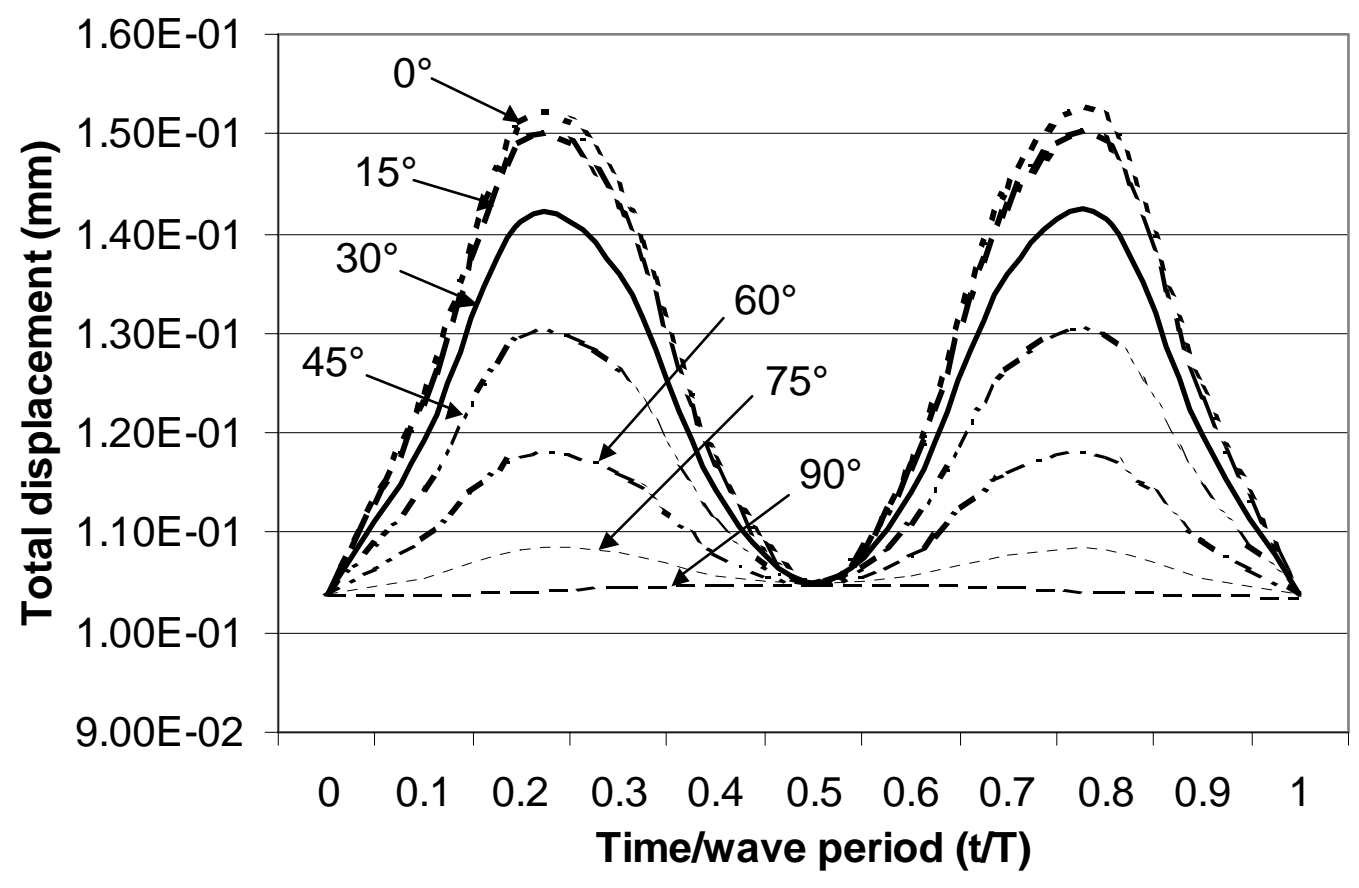

Figure 10(a) 


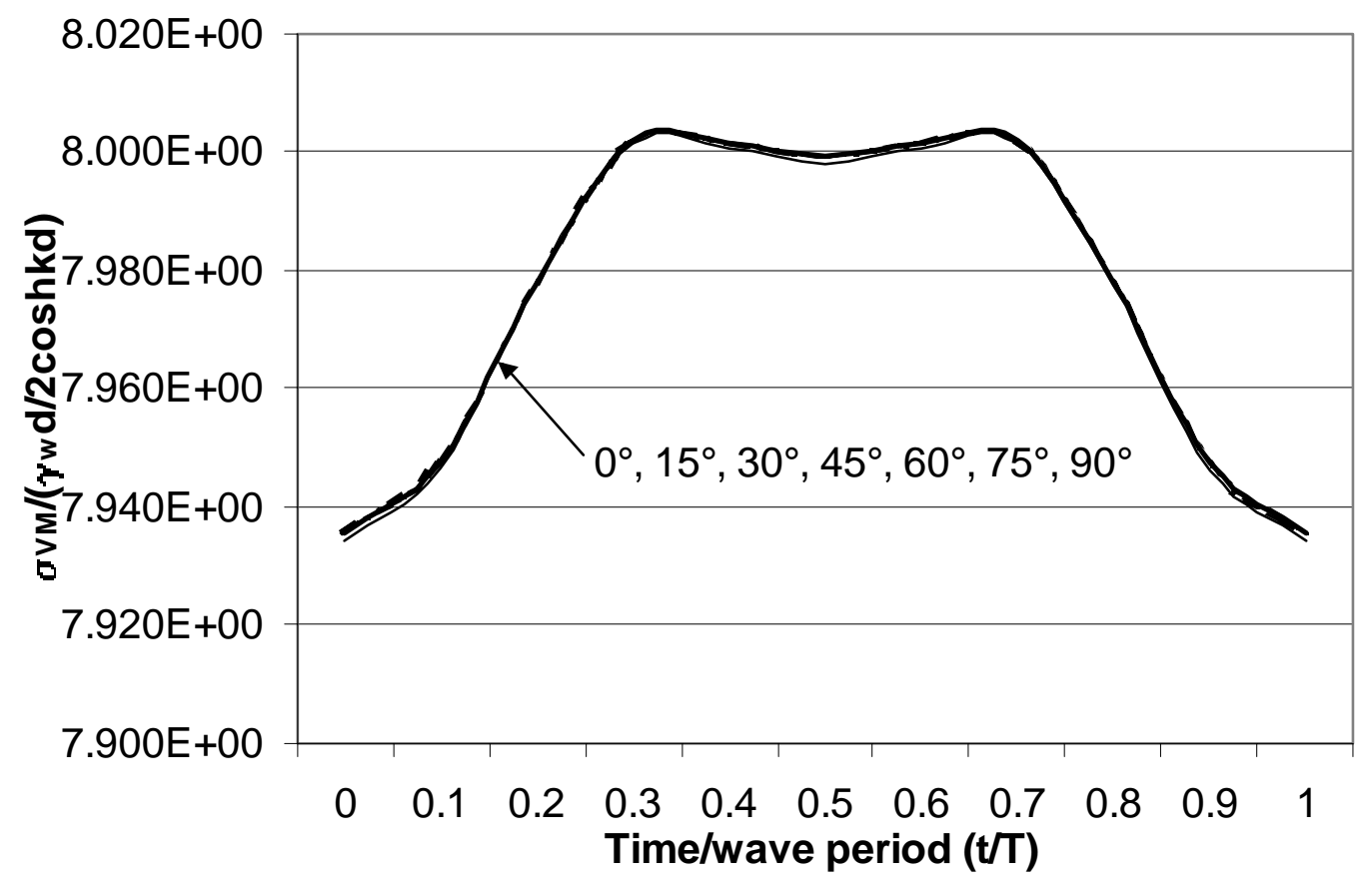

Figure 10(b) 


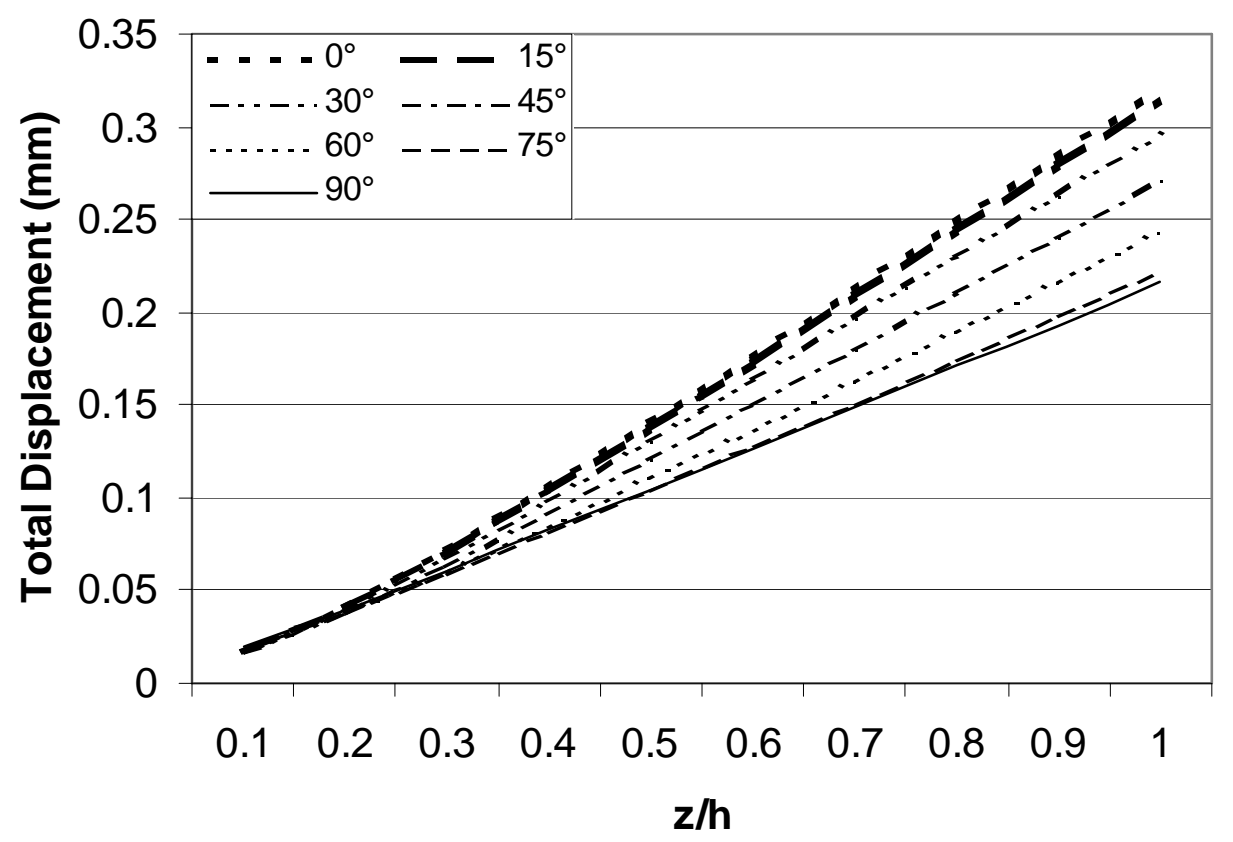

Figure 11(a) 


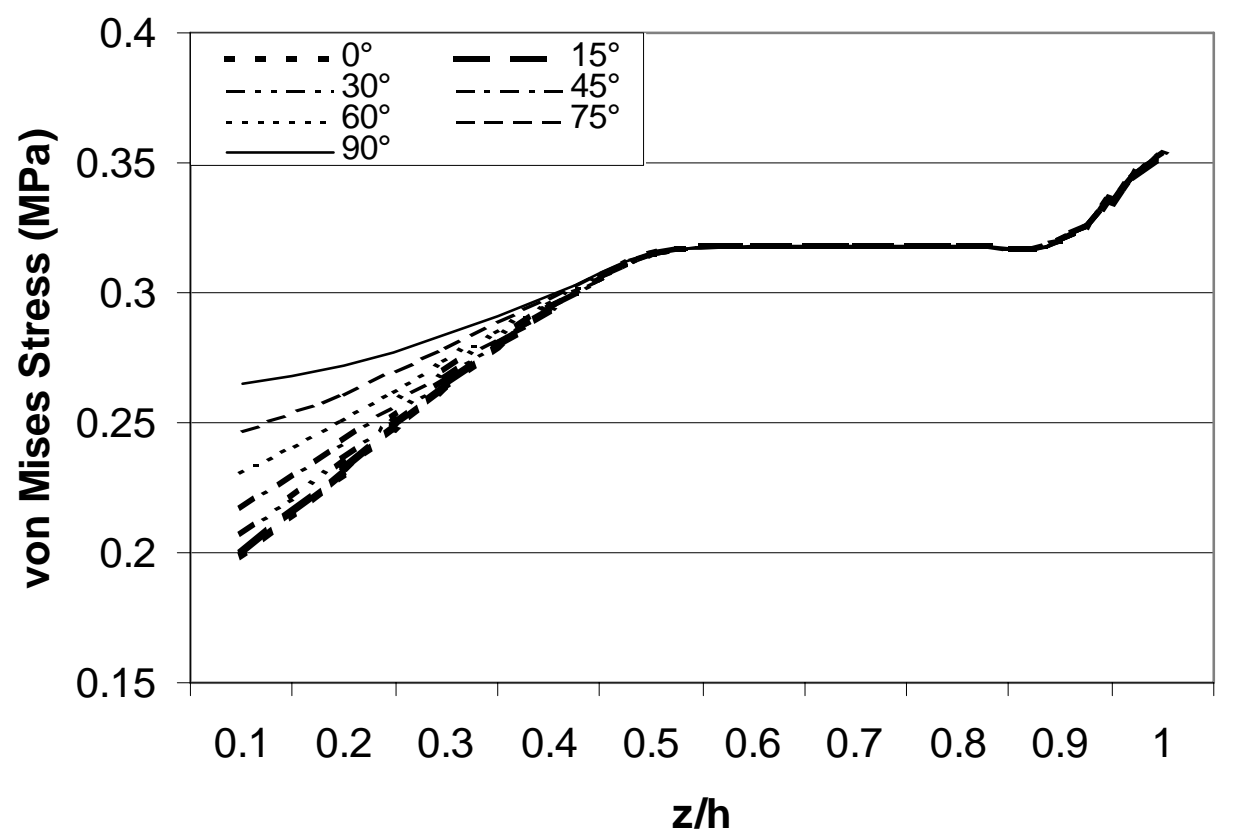

Figure 11(b) 


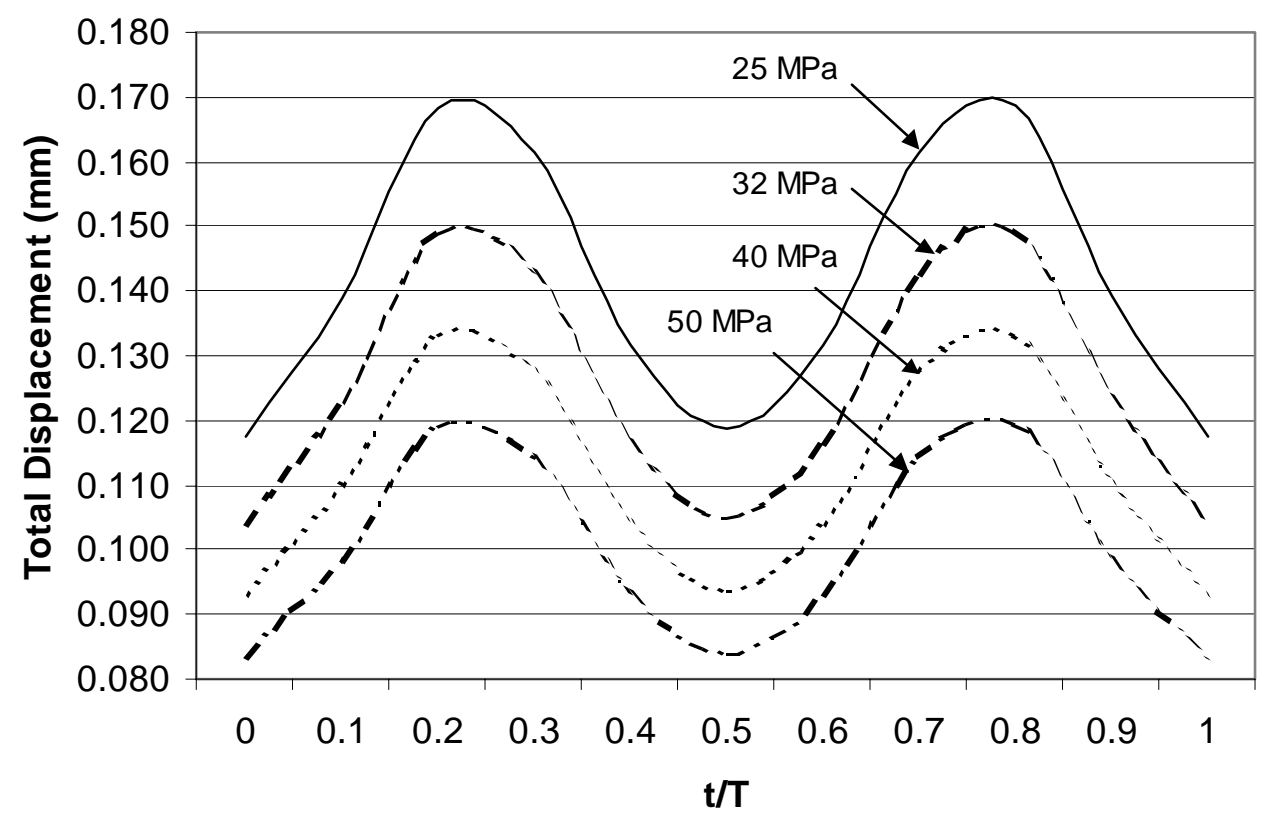

Figure 12(a) 


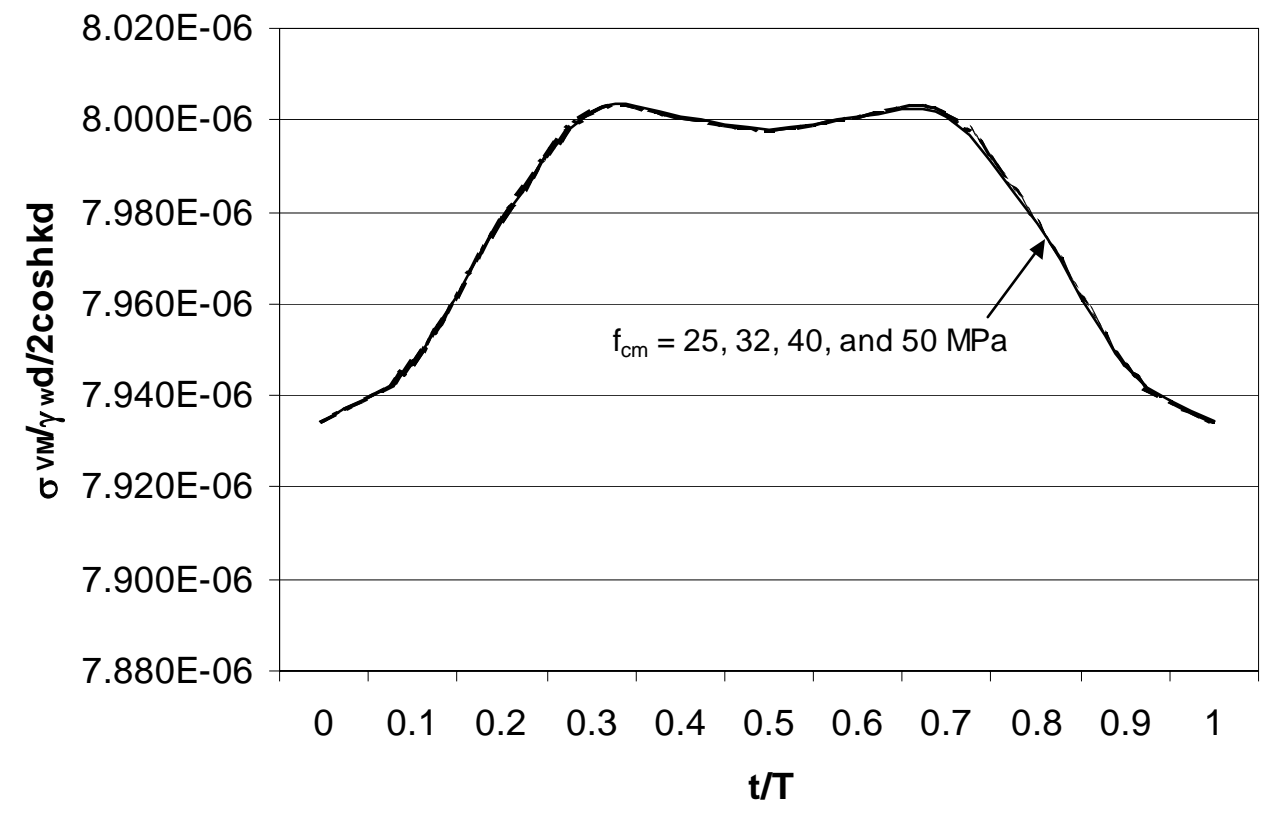

Figure 12(b) 


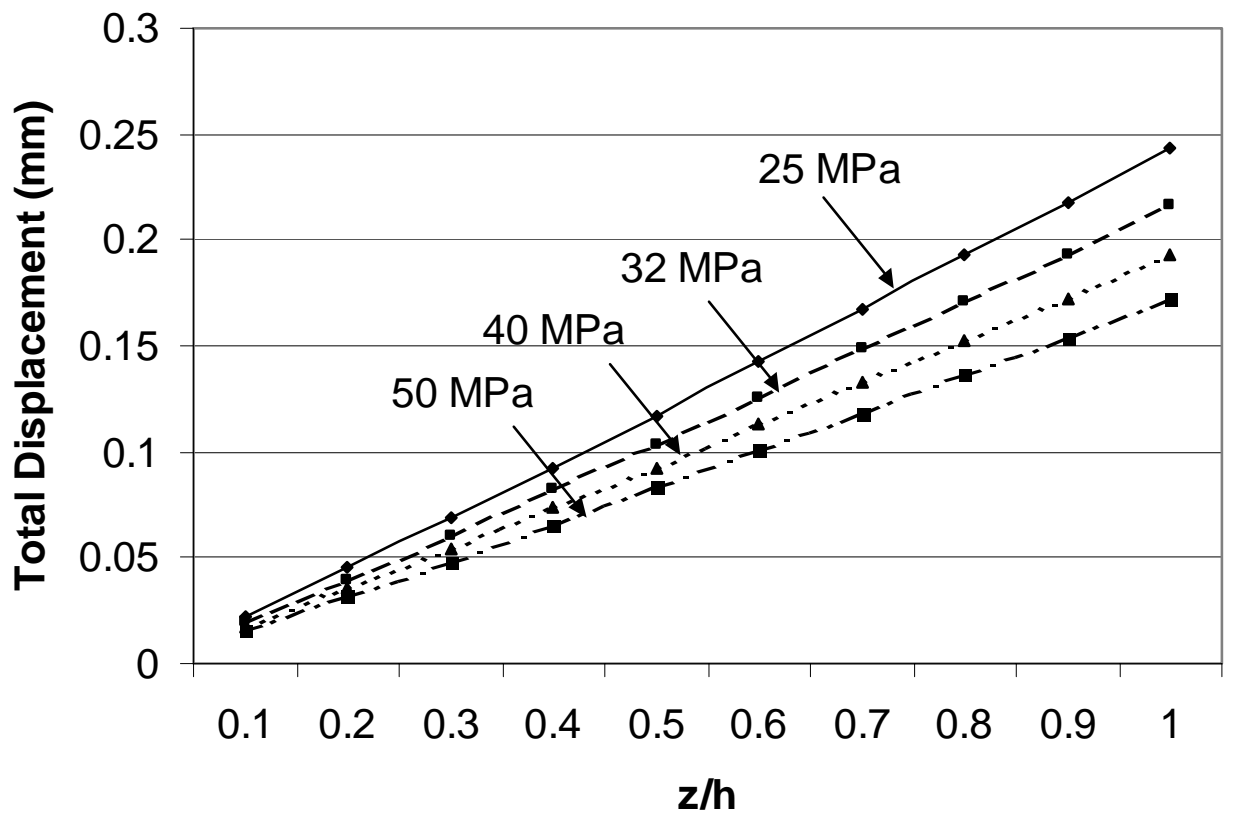

Figure 13(a) 


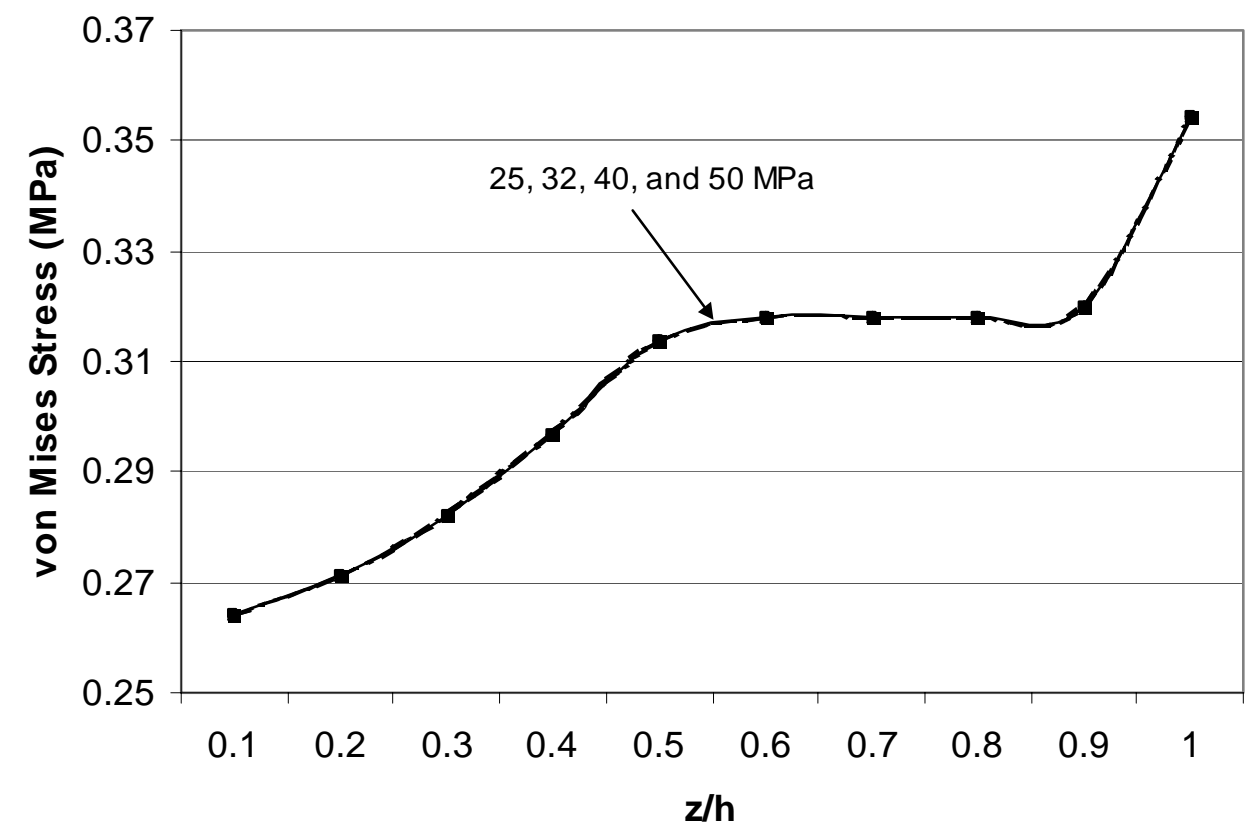

Figure 13(b) 


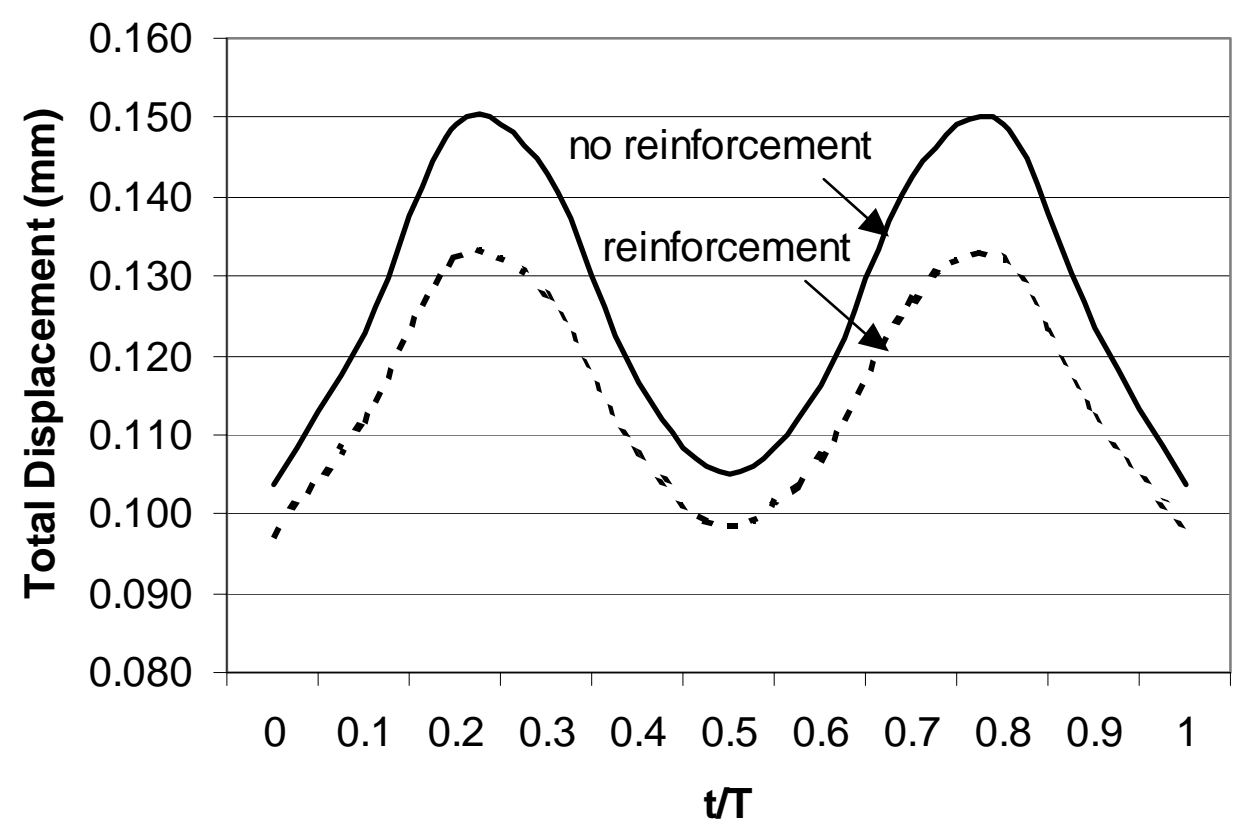

Figure 14(a) 


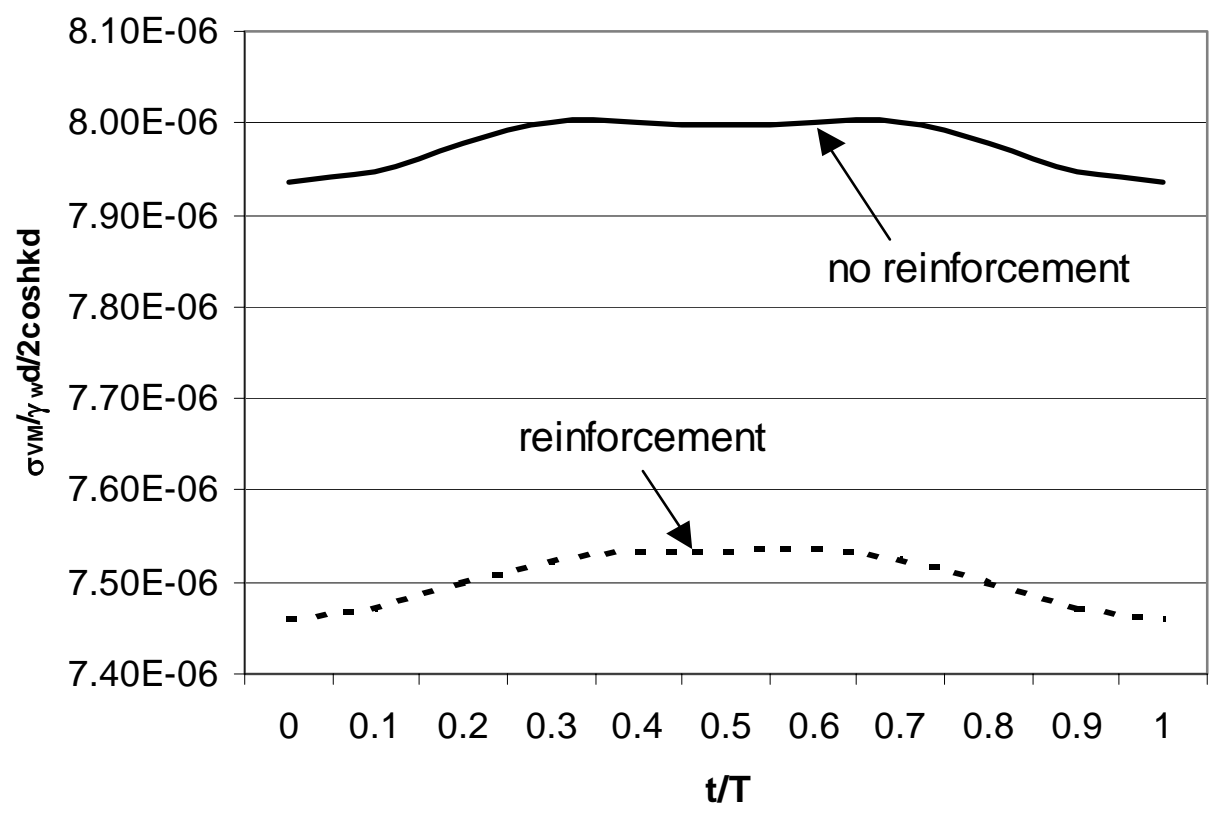

Figure 14(b) 


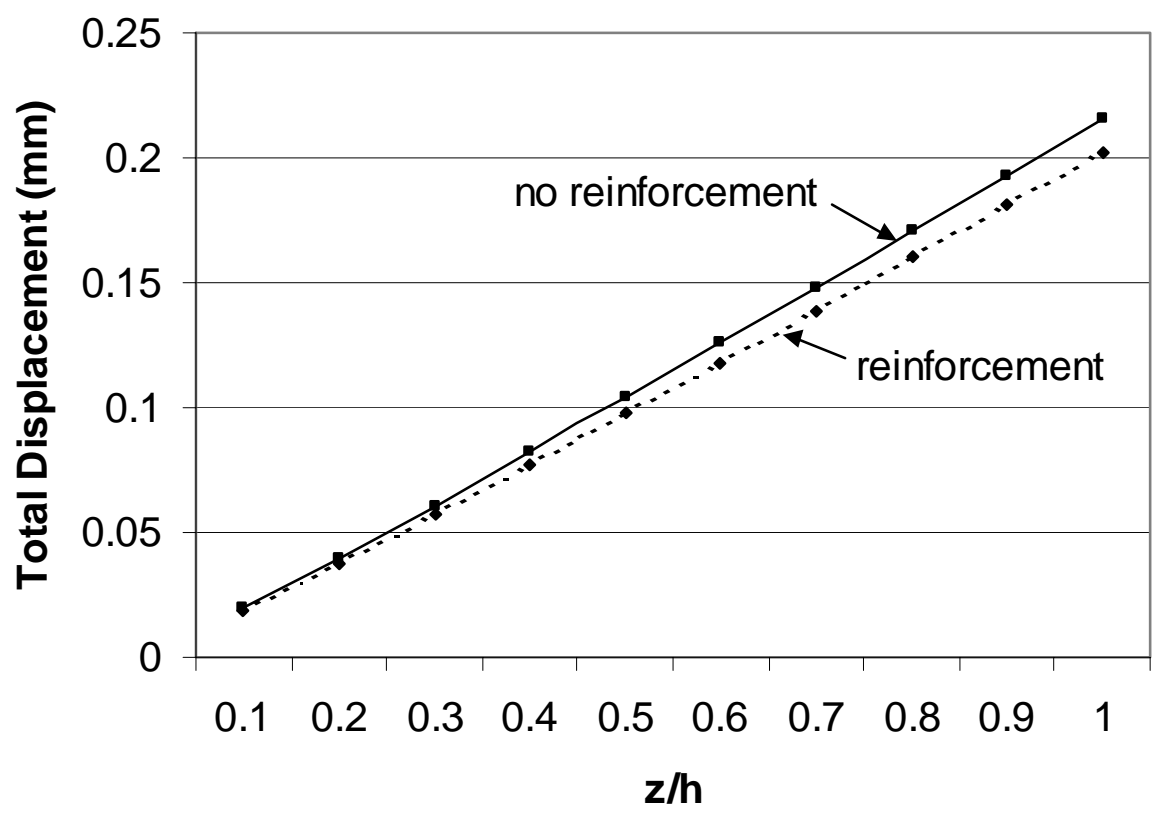

Figure 15(a) 


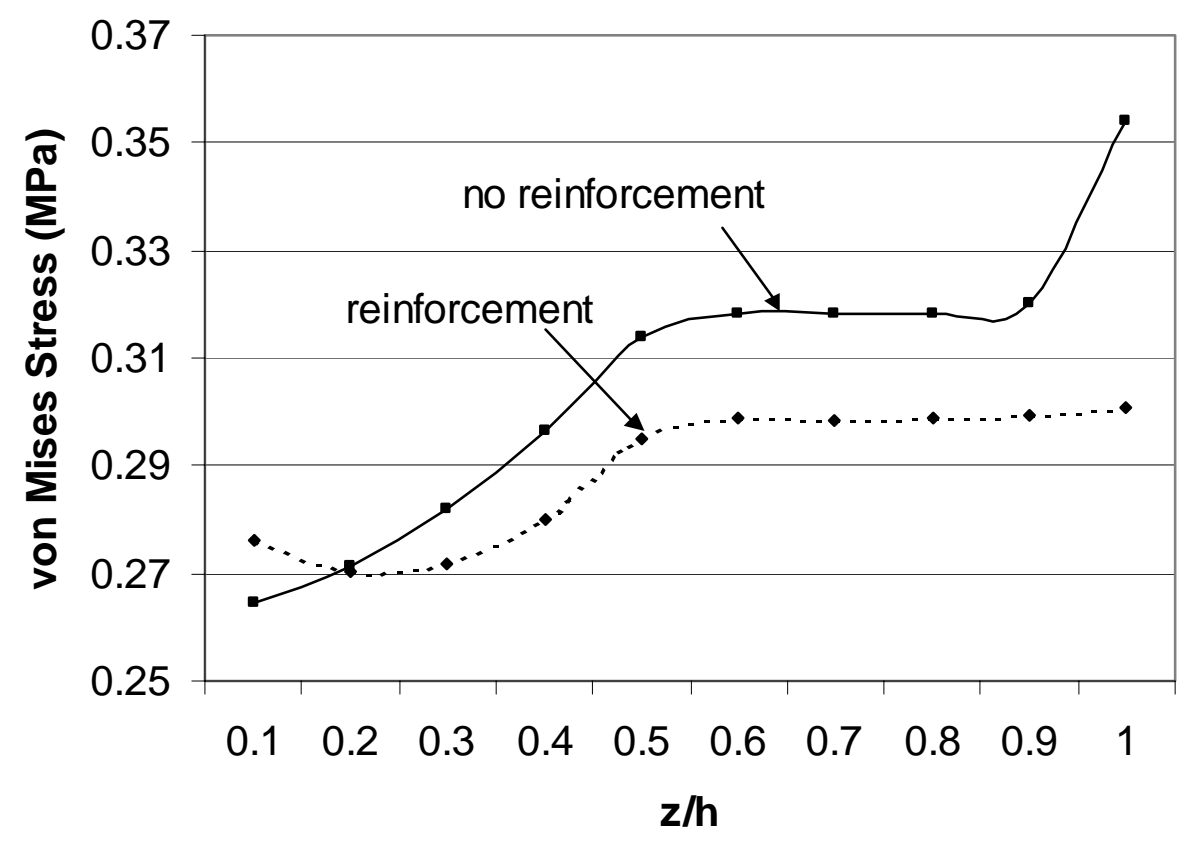

Figure 15(b) 


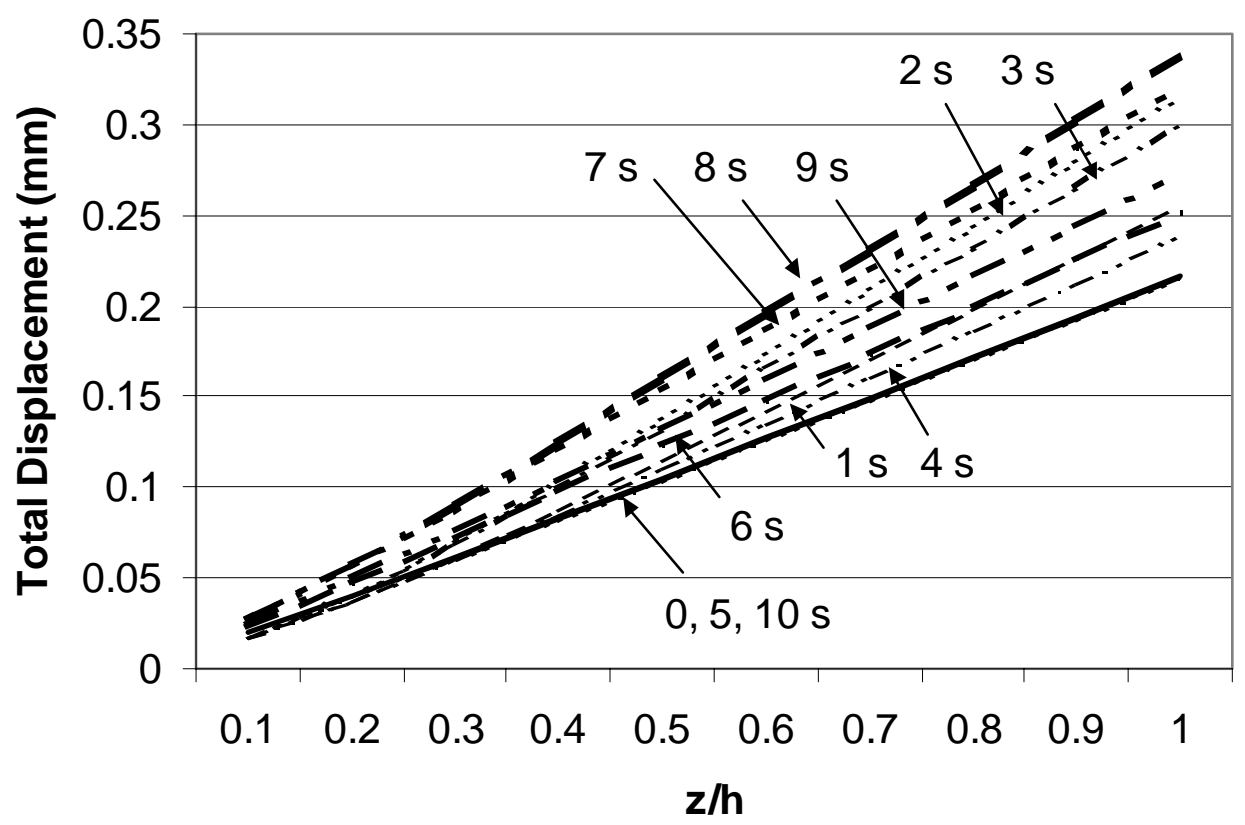

Figure 16(a) 


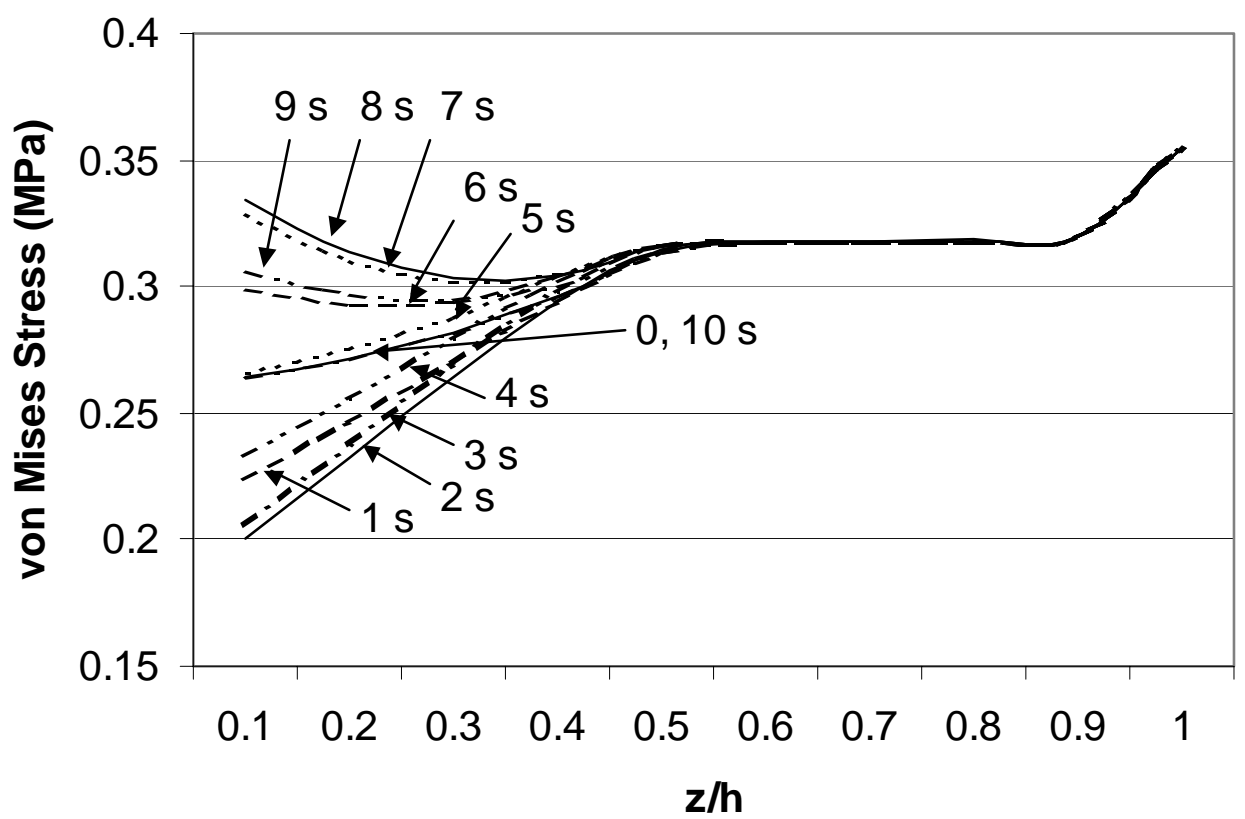

Figure 16(b) 